\title{
Title: Discovery of a Novel Inhibitor of Coronavirus 3CL Protease for the
}

\section{Potential Treatment of COVID-19}

\section{Short Title: Novel 3CL Protease Inhibitor for COVID-19}

Authors: Britton Boras ${ }^{1, \dagger}, \underline{\text { Rhys M. Jones }}^{1, \dagger}, *$, Brandon J. Anson ${ }^{9}$, Dan Arenson ${ }^{4}$, Lisa Aschenbrenner ${ }^{4}$, Malina A. Bakowski ${ }^{11}$, Nathan Beutler ${ }^{12}$, Joseph Binder ${ }^{1}$, Emily Chen ${ }^{11}$, Heather Eng ${ }^{4}$, Holly Hammond ${ }^{14}$, Jennifer Hammond ${ }^{6}$, Robert E. Haupt ${ }^{14}$, Robert Hoffman ${ }^{1}$, Eugene P. Kadar ${ }^{4}$, Rob Kania ${ }^{1}$, Emi Kimoto ${ }^{4}$, Melanie G. Kirkpatrick ${ }^{11}$, Lorraine Lanyon ${ }^{4}$, Emma K. Lendy ${ }^{10}$, Jonathan R. Lillis ${ }^{7}$, James Logue ${ }^{14}$, Suman A. Luthra ${ }^{3}$, Chunlong $\mathrm{Ma}^{8}$, Stephen W. Mason ${ }^{2,4}$, Marisa E. McGrath ${ }^{14}$, Stephen Noell ${ }^{4}$, R. Scott Obach ${ }^{4}$, Matthew N. O' Brien $^{5}$, Rebecca O'Connor ${ }^{4}$, Kevin Ogilvie ${ }^{4}$, Dafydd Owen ${ }^{3}$, Martin Pettersson ${ }^{3}$, Matthew R Reese $^{4}$, Thomas F. Rogers ${ }^{12,13}$, Michelle I. Rossulek ${ }^{3}$, Jean G. Sathish ${ }^{2}$, Norimitsu Shirai ${ }^{4}$, Claire Steppan $^{4}$, Martyn Ticehurst ${ }^{7}$, Lawrence W. Updyke ${ }^{3}$, Stuart Weston ${ }^{14}$, Yuao Zhu ${ }^{2}$, Jun Wang ${ }^{8}$, Arnab K. Chatterjee ${ }^{11}$, Andrew D. Mesecar ${ }^{9,10}$, Matthew B. Frieman ${ }^{14}$, Annaliesa S. Anderson ${ }^{2}$, Charlotte Allerton ${ }^{3}$

\section{Affiliations:}

${ }^{1}$ Worldwide Research and Development, Pfizer Inc., La Jolla, CA 92121, ${ }^{2}$ Pearl River, NY 10965, ${ }^{3}$ Cambridge, MA 02139, ${ }^{4}$ Groton, CT 06340, ${ }^{5}$ Lake Forest, IL 60045, ${ }^{6}$ Collegeville, PA 19426, USA, ${ }^{7}$ Sandwich, CT13 9ND, UK

${ }^{8}$ Department of Pharmacology and Toxicology, College of Pharmacy, University of Arizona, Tucson, AZ, 85721

${ }^{9}$ Department of Biological Sciences, ${ }^{10}$ Department of Biochemistry, Purdue University, West Lafayette, IN, 47907 USA.

${ }^{11}$ Calibr, a division of The Scripps Research Institute, La Jolla, CA 92037

${ }^{12}$ Department of Immunology and Microbiology, The Scripps Research Institute, La Jolla, CA 92037

${ }^{13}$ UC San Diego Division of Infectious Diseases and Global Public Health, UC San Diego School of Medicine, La Jolla, CA 92093.

${ }^{14}$ Department of Microbiology and Immunology University of Maryland School of Medicine, Baltimore, MD 21201 
$\uparrow$ These authors contributed equally to this work.

* To whom correspondence should be addressed. Email: rhys.jones@pfizer.com

One Sentence Summary: PF-07304814, a novel phosphate prodrug is disclosed as an investigational novel intravenous small molecule 3CL protease inhibitor for the potential treatment of COVID-19 and other coronavirus infections.

\author{
Abstract: \\ COVID-19 caused by the SARS-CoV-2 virus has become a global pandemic. 3CL protease is a \\ virally encoded protein that is essential across a broad spectrum of coronaviruses with no close \\ human analogs. The designed phosphate prodrug PF-07304814 is metabolized to PF-00835321 \\ which is a potent inhibitor in vitro of the coronavirus family 3CL pro, with selectivity over \\ human host protease targets. Furthermore, PF-00835231 exhibits potent in vitro antiviral activity \\ against SARS-CoV-2 as a single agent and it is additive/synergistic in combination with \\ remdesivir. We present the ADME, safety, in vitro, and in vivo antiviral activity data that \\ supports the clinical evaluation of this compound as a potential COVID-19 treatment.
}


Introduction: In December 2019, COVID-19 was identified as a new, potentially fatal, respiratory infection caused by severe acute respiratory syndrome coronavirus 2 (SARS-CoV$2)^{1,2}$. Unlike previous coronavirus outbreaks that receded relatively quickly, the resultant COVID-19 pandemic spread across the globe. As of December 2020, over 75 million people have been infected and over 1.6 million people have died globally with no approved drugs available to treat the disease ${ }^{3}$.

The RNA-dependent RNA polymerase ( $\mathrm{RdRp})$ inhibitor remdesivir is currently undergoing clinical investigation for the treatment of SARS-CoV-2 and was granted emergency use authorization by the U.S. Food and Drug Administration (FDA) in May 2020 ${ }^{4}$ To date, the results of trials of remdesivir have been mixed $^{5}$ despite being granted full authorization in October $2020^{6}$. Monoclonal antibodies that target the viral spike protein have also been successful in treating disease when applied at the early stage of infection ${ }^{7}$. Though the availability of highly efficacious vaccines provides great hope for the eradication of COVID-19, it is expected that it will still take time for cases to subside globally and does not address the potential threat of future coronaviruses. Thus, other classes of antivirals that exhibit single agent efficacy or that are complementary to remdesivir for use in combination regimens are essential to meet this substantial unmet need.

SARS-CoV-2 produces two large viral polyproteins, pp1a and pp1ab, which are processed by two virally encoded cysteine proteases, the main protease, also called 3C-like protease (3CL protease or 3CLpro) and the papain-like protease. Mutagenesis experiments with other coronaviruses have demonstrated that the activity of the 3CLpro is essential for viral 
replication $^{8,9}$. 3CLpro proteolytically processes the virus $\mathrm{p} 1 \mathrm{a} / \mathrm{p} 1 \mathrm{ab}$ polyproteins at more than 10 junctions to generate a series of non-structural proteins critical for virus replication and transcription, including RdRp, the helicase, and the 3CLpro itself ${ }^{10}$. No close human analogs of the coronavirus 3CLpro are known, suggesting that selective 3CLpro inhibitors should avoid unwanted polypharmacology ${ }^{11}$. The essential functional importance of proteases in virus replication has led to the clinical success of protease inhibitors in combating both human immunodeficiency virus (HIV) and hepatitis C virus (HCV) ${ }^{12-14}$. This together with the opportunity for selectivity, makes 3CLpro an attractive antiviral drug target ${ }^{15}$.

Following the severe acute respiratory syndrome (SARS) outbreak in 2002-2003 we identified a potential small molecule protease inhibitor (PF-00835231) for the treatment of SARS-CoV-1, using structure-based drug design ${ }^{16}$. Due to the SARS pandemic being brought under control in July 2003 following public health measures which incorporated patient isolation and travel restrictions, this project was discontinued due to the lack of a path forward to demonstrate clinical efficacy. Given that the SARS-CoV-1 and SARS-CoV-2 3CLpro sequences share 96\% identity overall and $100 \%$ identity in the active site $e^{1,17,18}$, following the emergence of SARSCoV-2, PF-00835231 was identified as a potential SARS-CoV-2 3CLpro inhibitor for the treatment of COVID-19 disease ${ }^{16}$. Subsequent antiviral data presented here indicate that PF00835231 has similar potency against either SARS-CoV-1 or SARS-CoV-2 (Table S1).

Herein we describe the 3CLpro inhibitor, PF-00835231, and its novel phosphate prodrug, PF07304814, and present broad-spectrum inhibitory activity across coronaviral 3CL proteases, in vitro and in vivo antiviral activity in a coronavirus animal model, and absorption, distribution, 
metabolism, excretion (ADME) and safety data highlighting its potential for the intravenous (IV) treatment of COVID-19 disease.

\section{Results and Discussion}

$\underline{\text { PF-00835231 exhibits tight and specific binding to SARS-CoV-2 3CL in vitro }}$

A thermal-shift assay was used to evaluate the direct binding between PF-00835231 and SARSCoV-2 3CLpro. The melting temperature of SARS-CoV-2 3CLpro was shifted by $14.6^{\circ} \mathrm{C}$ upon binding of PF-00835231, from $55.9 \pm 0.11^{\circ} \mathrm{C}(\mathrm{n}=16)$ to $70.5 \pm 0.12^{\circ} \mathrm{C}(\mathrm{n}=8)$. These data support tight and specific binding of PF-00835231 to SARS-CoV-2 3CLpro (Fig. 1) as was shown previously by $\mathrm{X}$-ray co-crystal structure and evaluation of $\mathrm{Ki}^{16}$.

$\underline{\text { PF-00835231 has potent and broad-spectrum inhibitory activity against a panel of coronavirus }}$ 3CLpros

To explore the notion that PF-00835231 could have pan-coronavirus activity, PF-00835231 was evaluated against 3CLpro from a variety of other coronaviruses representing alpha, beta and gamma groups of Coronaviridae, using biochemical Förster Resonance Energy Transfer (FRET) protease activity assays. PF-00835231 demonstrated potent inhibitory activity against all tested coronavirus 3CLpro including members of alpha-coronaviruses (NL63-CoV, PEDV, FIPV), beta-coronaviruses (HKU4-CoV, HKU5-CoV, HKU9-CoV, MHV-CoV, OC43-CoV, HKU1$\mathrm{CoV}$ ), and gamma-coronavirus (IBV-CoV), with Ki values, ranging from $30 \mathrm{pM}$ to $4 \mathrm{nM}$ (Table 1). The demonstrated activity is consistent with a potential therapeutic use against emerging coronaviruses. This inhibitory activity is restricted to coronavirus 3CLpros as PF-00835231 was 
inactive against a panel of human proteases and HIV protease (Table S2). PF-00835231 showed detectable activity against human cathepsin B but 1000-fold weaker (6.9 nM vs $6 \mu \mathrm{M})$ activity compared to 3CLpro (Table S2). Thereby, these data collectively support PF-00835231 is a selective in vitro protease inhibitor with broad coronavirus activity.

$\underline{\text { In vitro cellular antiviral activity of PF-00835231 against SARS-CoV-2 }}$

The antiviral activity of PF-00835231 against SARS-CoV-2 in cell culture was evaluated with a cytopathic effect (CPE) assay using either VeroE6 kidney cells enriched for angiotensinconverting enzyme 2 (ACE2) (VeroE6-enACE2) receptor or VeroE6 cells constitutively expressing EGFP (VeroE6-EGFP). These cell lines were infected with the SARS-CoV-2 Washington strain 1 (WA1 - EPI_ISL_404895) or the Belgium/GHB-03021/2020 strain (GHB03021 - EPI_ISL_407976) ${ }^{19}$, respectively, which have identical 3CLpro amino acid sequences. PF-00835231 exhibited viral CPE EC 50 values of $39.7 \mu \mathrm{M}$ and $88.9 \mu \mathrm{M}$, respectively $\left(\mathrm{EC}_{50}\right.$, Fig. 2). However, Vero cells express high levels of the efflux transporter P-glycoprotein (P-gp) (also known as MDR1 or ABCB1), of which PF-00835231 is a known substrate ${ }^{16}$ suggesting that the intracellular concentration of PF-00835231 was lower than it initially appeared. Therefore, to evaluate the full potency of PF-00835231, the assays were repeated in the presence of a P-gp efflux inhibitor, CP-100356 ${ }^{20}$. PF-00835231 exhibited a 117 - to 173 -fold increase in activity in the presence of $2 \mu \mathrm{M}$ P-gp inhibitor, with $\mathrm{EC}_{50}$ values of $0.23 \mu \mathrm{M}$ in VeroE6-enACE2 cells and $0.76 \mu \mathrm{M}$ in the VeroE6-EGFP cells (Fig. 2). The P-gp inhibitor alone had no antiviral or cytotoxic activity at these concentrations and did not cause cytotoxicity in the presence the protease inhibitor. The use of VeroE6 cells by many in the field to evaluate inhibitor activity could be problematic, since the true activity of some compounds could be masked by efflux of 
inhibitors from these cells (Fig. 2B). Consistent with many viral protease inhibitors ${ }^{21}$, there was a steep response to increasing doses of PF-00835231, with a 2-3 fold difference between $\mathrm{EC}_{50}$ and $\mathrm{EC}_{90}$ in both cell types $\left(\mathrm{EC}_{90}=0.48 \mu \mathrm{M}\right.$ in VeroE6-enACE2 cells and $\mathrm{EC}_{90}=1.6 \mu \mathrm{M}$ in VeroE6-EGFP cells in the presence of the P-gp inhibitor). As expected, when lung cell lines were tested for antiviral potency in the presence and absence of P-gp inhibitor (A549-ACE2 22 and MRC5), no statistical difference in antiviral potency was observed (Fig. 2A). Additionally, antiviral activities in both VeroE6 cell lines with $2 \mu \mathrm{M}$ P-gp inhibitor are similar to those observed in more physiologically relevant human lung cell culture systems, including A549ACE2 and polarized human airway epithelial cells ${ }^{22}$, where P-gp expression is lower. These data support the potential for single agent antiviral activity. As will be presented later, despite seeing apparent antiviral activity for PF-07304814, a prodrug of PF-00835231, in cell-based assays (Fig. 2A) this activity is likely due to conversion of PF-07304814 to PF-00835231 in the assay.

\section{$\underline{\text { Potential for antiviral combination benefit of PF-00835231 in combination with remdesivir }}$}

Combinations of antiviral agents, especially those targeting different steps in the virus replication cycle, are a frequently employed therapeutic strategy in treating viral diseases ${ }^{23}$. As PF00835231 and remdesivir, a nucleoside RNA-dependent RNA polymerase inhibitor, target different steps in the virus replication cycle, the antiviral activity of the two compounds was evaluated alone and in combination using HeLa-ACE2 cells ${ }^{24}$. Viral proteins were detected in this assay using convalescent human polyclonal sera from two different COVID-19 patients. PF00835231 alone inhibited SARS-CoV-2 replication with an average $\mathrm{EC}_{50}$ of $0.13 \mu \mathrm{M}$ and $\mathrm{EC}_{90}$ of $0.43 \mu \mathrm{M}$; whereas remdesivir had an average $\mathrm{EC}_{50}$ of $0.074 \mu \mathrm{M}$ and $\mathrm{EC}_{90}$ of $0.17 \mu \mathrm{M}$ (Fig. 3A). Combination studies were performed using a drug testing matrix, and the data for the drug 
combination were analyzed using reference models (Loewe, Bliss, HSA) to classify the effects of the drug combination as either additive, synergistic or antagonistic (isobologram, synergy scores, and combination indices).

As summarized in Fig. 3B, the combination of PF-00835231 and remdesivir using patient sera for detection, exhibited synergy in two independent experiments with sera from patient \#1 and additivity in a single experiment with sera from patient \#2 (Fig. 3B). The different classification is most likely due to the different convalescent serum used as detection reagents. These same antiviral data were also analysed using Synergyfinder, which also indicated that the two drugs were additive to synergistic, with a representative graph shown in Fig. 3B. Antagonism was not demonstrated for the combination of PF-00835231 and remdesivir in these studies. The observed additivity/synergy was not due to cytotoxicity, as there was no noticeable cytotoxicity in virus infected host cells for all the combinations tested. This additivity/synergy is similar to other protease inhibitors used for the treatment of $\mathrm{HCV}$, which has led to substantial clinical benefit ${ }^{25}$.

\section{Activity of PF-00835231 in a mouse model of SARS-CoV-1 infection:}

Human coronaviruses can replicate in mice but do not cause disease. The poor replication is due to differences between the human and mouse orthologs of the primary SARS-CoV-1 and CoV-2 receptor, ie, ACE2, unless the virus is first mouse-adapted (MA) ${ }^{26}$. Given the sequence identity between SARS-CoV-1 and SARS-CoV-2 3CL proteases, especially in the active site (100\%), it was expedient to evaluate PF-00835231 in the validated SARS-CoV MA15 model ${ }^{19}$. SARSCoV-MA15 has two mutations in $3 \mathrm{CL}$ protease coding sequence ${ }^{27}$ that are located distal to the active site that did not influence activity of the protease or its inhibition by PF-00835231 (Table 
S1). Treatment of MA15-infected BALB/c mice with $100 \mathrm{mg} / \mathrm{kg}$ PF-00835231 twice daily (BID) by subcutaneous (S.C.) injection, started either at the same time as infection, ie, day 0, or on day 1 or 2 post-infection (Fig. 4A). This resulted in a significant $1-2 \log _{10}$ (Fig. 4B) reduction in lung viral titers, respectively, when measured on day 4 . When the mice were treated with 30,100 , or $300 \mathrm{mg} / \mathrm{kg}$ (S.C., BID), a dose dependent reduction in lung viral titers of $\geq 3 \log _{10}$ was observed (Fig. 4C). An assessment of plasma exposure was made following $100 \mathrm{mg} / \mathrm{kg}$ and 300mg/kg in non-infected animals and the unbound concentrations at $12 \mathrm{~h}(\mathrm{Cmin})$ were approximately 500nM $\left(\sim 1 \mathrm{x}\right.$ in vitro $\left.\mathrm{EC}_{90}\right)$ and $1700 \mathrm{nM}\left(\sim 3 \mathrm{x}\right.$ in vitro $\left.\mathrm{EC}_{90}\right)$ respectively. No assessment of the $30 \mathrm{mg} / \mathrm{kg}$ exposures were made at the time of the experiment. Infected-mice that were treated with 300 mg/kg PF-00835231 starting on day 0 did not lose as much weight as vehicle-treated or infected, untreated animals (Fig. 4D). Microscopic evaluation of lung tissue showed that PF-00835231treatment prevented or decreased histopathologic signs compared to vehicle-treated animals (Fig. 4E). Therefore, PF-00835231 was active in vivo when added at the time of infection or as treatment (delayed to day 1 or day 2, post-infection), alleviated signs of disease (weight loss and lung pathology), and drug exposure approximately equivalent to the in vitro $\mathrm{EC}_{90}$ was sufficient to achieve the maximal $2-3 \log _{10}$ reduction in lung viral titers.

$\underline{\text { Favorable preclinical ADME and pharmacokinetic profile of PF-00835231 }}$

The metabolic stability of PF-00835231 was evaluated in vitro using pooled human liver microsomes (HLM). PF-00835231 was shown to be metabolized by cytochrome P450 enzymes exhibiting an unbound $\mathrm{CL}_{\text {int }} 14 \mu \mathrm{L} / \mathrm{min} / \mathrm{mg}$. Using recombinant heterologously expressed enzymes and HLM with the CYP3A selective inhibitor ketoconazole, CYP3A4 was identified as the major CYP involved in the metabolism of PF-00835231 (Table S3). It was also noted that the 
polymorphically expressed CYP3A5 can also metabolize PF-00835231 and that clearance may be slightly greater in CYP3A5 expressers. The potential for PF-00835231 to reversibly inhibit human cytochrome P450 enzymes (CYP1A2, 2B6, 2C8, 2C9, 2C19, 2D6, and 3A) was evaluated using probe substrates in pooled HLM and provided IC $_{50}$ values > $200 \mu$ M (Table S4) and a weak signal for time dependent inhibition (TDI) of CYP3A4/5 (Table S5). These data indicate PF-00835231 provides a low risk of causing drug-drug interactions (DDIs) on coadministration with other drugs. The potential for PF-00835231 to inhibit a range of transporters (BCRP, P-gp, OATP1B1/1B3, OCT1/2, OAT1/3 and MATE1/2K) was evaluated using in vitro systems (Table S6). The $\mathrm{IC}_{50}$ values were $>20 \mu \mathrm{M}$ and indicate a low risk of causing DDIs due to transporter inhibition at the projected clinical exposure. The plasma protein binding of PF-00835231 was measured across species using equilibrium dialysis and demonstrated moderate binding to plasma proteins with plasma unbound fractions of 0.33 to 0.45 across species (Table S7).

PF-00835231 was administered IV to rats, dogs and monkeys ( 1 or $2 \mathrm{mg} / \mathrm{kg}$ ) and exhibited moderate plasma clearances $(50-80 \%$ liver blood flow), low volumes of distribution $(<1.5 \mathrm{~L} / \mathrm{kg})$ and short half-lives ( $<2$ hours) across species in keeping with its lipophilic $\left(\log D_{7.4}=1.7\right)$ and neutral physiochemistry. Following oral administration to rats $(2 \mathrm{mg} / \mathrm{kg})$ and monkeys (5 $\mathrm{mg} / \mathrm{kg}$ ) PF-00835231 exhibited low oral bioavailability $(<2 \%)$, likely due to a combination of low absorption because of its low permeability (apparent MDCK-LE permeability of $1.3 \times 10^{-}$ ${ }^{6} \mathrm{~cm} / \mathrm{sec}^{28,29}$ ), low solubility, potential for active efflux in the gut by P-gp and BCRP, and the potential for amide hydrolysis by digestive enzymes in the gastrointestinal tract. In rat, dog and monkey approximately $10 \%$ or less of PF-00835231 was eliminated unchanged in the urine 
indicating renal elimination may also play a minor role in the clearance of PF-00835231 in humans (Table S8).

$\underline{\text { Human pharmacokinetic predictions suitable for IV administration }}$

Taking into account the human in vitro metabolism data and in vivo pharmacokinetic (PK) data in rats, dogs and monkeys, PF-00835231 was predicted to exhibit a plasma clearance $\left(\mathrm{CL}_{\mathrm{p}}\right)$ of $\sim 6 \mathrm{~mL} / \mathrm{min} / \mathrm{kg}$ (major CYP, minor renal pathways), steady state volume of distribution ( $\mathrm{V}_{\mathrm{dss}}$ ) of $1 \mathrm{~L} / \mathrm{kg}$ and half-life of approximately 2 hours in humans. Due to the limited oral bioavailability, short elimination half-life, and the likely need to maintain unbound systemic concentrations over time to achieve antiviral activity, a continuous IV infusion was proposed as the optimal dosing route and regimen.

\section{$\underline{\text { Efficacious target concentration and feasible human dose projection }}$}

The projected minimally efficacious concentration $\left(\mathrm{C}_{\mathrm{eff}}\right)$ was chosen to match the in vitro $\mathrm{EC} 90$ (See supplemental methods for rationale), consistent with the preclinical to clinical translation of approved protease inhibitors ${ }^{30}$. Since PF-00835231 was proposed to be administered by continuous infusion, the projected steady-state exposure is equal to the $\mathrm{C}_{\min }$ maintained over the dosing interval. The dose response assay performed in the most physiologically relevant cell type, human lung carcinoma, resulted in an average $\mathrm{EC}_{90}$ value of $0.44 \mu \mathrm{M}^{22}$. This is consistent with additional antiviral data in Hela-ACE2 cells $\left(\mathrm{EC}_{90}=0.4 \mu \mathrm{M}\right)$ and Vero cell lines $\left(\mathrm{EC}_{90}=0.48\right.$ $1.6 \mu \mathrm{M})$ when a P-gp inhibitor was added to better reflect the lack of substantial P-gp transporter in the lung (Fig. 2B). Furthermore, the antiviral inhibition is supported by the antiviral time course experiment performed in a primary human airway epithelial model (preliminary data 
indicates an unbound $\left.\mathrm{EC}_{90}<0.5 \mu \mathrm{M}\right)^{22}$, indicating a consistent intrinsic anti-SARS-CoV-2 activity of PF-00835231 across different cell types. Therefore, the proposed minimal $\mathrm{C}_{\text {eff }}$ is $\sim 0.5 \mu \mathrm{M}$ unbound.

Due to the rapid blood perfusion through the lungs and the continuous steady state intravenous infusion regimen, the unbound plasma and unbound lung concentrations are assumed to be in equilibrium and, therefore, the unbound plasma concentration provides a reasonable surrogate for the concentration at the main site of action of the disease. Based on the human PK predictions, the minimally efficacious dose of PF-00835231 necessary to achieve this exposure is $\sim 320 \mathrm{mg}$ /day administered as an intravenous continuous infusion. The required duration of dosing for efficacy remains uncertain and will need to be evaluated in humans.

Formulation and solubility profile of PF-00835231 to enable IV administration

PF-00835231 is a moderately lipophilic $\left(\log \mathrm{D}_{7.4}=1.7\right)$, neutral molecule with no ionizable centers throughout the physiologically relevant $\mathrm{pH}$ range. Consequently, PF-00835231 exhibits a $\mathrm{pH}$ independent solubility with an intrinsic aqueous solubility of less than $0.1 \mathrm{mg} / \mathrm{mL}$ and limited opportunities for solubility-enabling formulation approaches. Preliminary work using standard solubilizing excipients indicated that achieving a solubility $>0.5 \mathrm{mg} / \mathrm{mL}$ would likely be challenging.

Based on a maximum desired intravenous infusion volume of $\sim 1 \mathrm{~L}$ per day a solubility of $0.5 \mathrm{mg} / \mathrm{mL}$ would be sufficient to deliver the minimal efficacious dose estimate of $\sim 320 \mathrm{mg} /$ day to maintain a $\sim 0.5 \mu \mathrm{M}$ steady state unbound concentration (Fig. $5 \mathrm{~B}$ ). Due to the nascent 
understanding of the virus, the required target levels of inhibition for clinical benefit remain uncertain and the ability to evaluate exposures up to $\sim 10 \mathrm{x} \mathrm{C}_{\text {eff }}$ in early clinical development is desirable. As a potential option to increase exposures, and/or decrease the required infusion volume, the use of a strong CYP3A inhibitor (itraconazole 200mg QD for 15 days) was considered but preliminary, physiologically-based pharmacokinetic (PBPK) modeling predicted only a 2-fold increase in PF-00835231 exposure at steady state (Table S11).

The ability to achieve higher doses could also potentially mitigate a higher than predicted clearance, or variations in patient body weight. Therefore, a medicinal chemistry strategy to significantly enhance the aqueous solubility of PF-00835231, by designing a phosphate prodrug was pursued.

\section{Considering an intravenous phosphate prodrug approach to improve solubility}

IV phosphate prodrugs have precedence with several commercially available drugs such as fosfluconazole and fosphenytoin which are rapidly cleaved by human alkaline phosphatase to provide high systemic exposures of their respective active moieties following IV administration (Fig. 5) ${ }^{31,32}$. Alkaline phosphatase is ubiquitously expressed across tissues with high levels expressed in the liver, lung, and kidney (Alkaline phosphatase tissue data from v19.proteinatlas.org ${ }^{33}$ ). High levels of conversion from prodrug to active moiety for fosfluconazole and fosphenytoin have also been observed in rats and dogs supporting cross species translation to human for the conversion of prodrug to active moiety ${ }^{32,34}$. Overall, the use of a phosphate prodrug is an established approach for IV administration to provide rapid conversion to its active moiety and was considered for PF-00835231. 


\section{Synthetic route to provide phosphate prodrug}

The synthesis of PF-00835231 has been described previously ${ }^{16}$. The subsequent synthesis of the phosphate prodrug of PF-00835231 was achieved via two steps (Fig. S1). Briefly, treatment of 1 (PF-00835231) with di-tert-butyl N,N-dipropan-2-ylphosphoramidite and tetrazole in tetrahydrofuran followed by oxidation with aqueous hydrogen peroxide delivered intermediate 2 . The phosphate $t$-butyl groups were subsequently hydrolyzed using trifluoroacetic acid in dichloromethane to deliver phosphate prodrug 3 (PF-07304814) as a solid.

Enhanced formulation and solubility profile of PF-07304814 to provide clinical flexibility

PF-07304814 rapidly undergoes in vivo conversion to the active metabolite PF-00835231 (Fig. S2A). The phosphate prodrug is weakly acidic, with pKas of 1 and 6.4 , and a predicted $\log \mathrm{D}_{7.4}$ of -3.7. At $\mathrm{pHs}$ above the compound's first $\mathrm{pKa}$, the phosphate functional group is de-protonated and negatively charged, which enables a significant improvement in aqueous solubility to greater than $200 \mathrm{mg} / \mathrm{mL}$ over a $\mathrm{pH}$ range compatible with intravenous infusion. The higher intrinsic solubility of PF-07304814 eliminates the need for solubility-enabling formulations and enables the use of standard IV compatible excipients. Furthermore, the improved solubility enables higher doses to be explored in the clinic and gives clinicians greater flexibility in terms of dose volume to account for patient-specific co-administration requirements.

$\underline{\text { PF-07304814 (prodrug) preclinical in vitro and in vivo ADME profile }}$

To understand the metabolic stability and conversion of PF-07304814 to its active moiety (PF00835231), PF-07304814 enzyme kinetics were evaluated in vitro using liver S9 fractions and 
was shown to exhibit rapid conversion to PF-00835231 with unbound $\mathrm{CL}_{\text {int }}$ values of 51, 84, 168 and $428 \mu \mathrm{L} / \mathrm{min} / \mathrm{mg}$ in rat, dog, monkey and human respectively. In these in vitro systems, PF00835231 was the only metabolite formed from PF-07304814. Conversion was rapid in phosphate-free incubations but abolished in the presence of phosphate buffer supporting the role of alkaline phosphatase in this conversion (Table S9, Fig. S2). To evaluate the in vivo conversion and systemic availability of the active moiety PF-00835231, PF-07304814 was administered intravenously to rats, dogs and monkeys. PF-07304814 exhibited high conversion to PF00835231, systemic clearance and short half-life across species forming 68, 81, 76\% PF00835231 in rats, dogs and monkey, respectively, in comparison to the systemic exposure achieved with IV administration of PF-00835231 (Fig. 6A and Table S8).

PF-07304814 was also evaluated for the potential to cause reversible and time dependent inhibition of human cytochrome P450 enzymes using pooled HLM and probe substrates for a range of CYP enzymes (CYP1A2, 2C8, 2C9, 2C19, 2D6, and 3A4/5) and showed low risk with $\mathrm{IC}_{50}$ values $>100 \mu \mathrm{M}$ and no evidence of TDI (Table S4). The potential for PF-07304814 to inhibit a range of transporters (BCRP, P-gp, OATP1B1/1B3, OCT1/2, OAT1/3 and MATE1/2K) was evaluated using in vitro systems providing $\mathrm{IC}_{50}$ values $>130 \mu \mathrm{M}$ indicating a low risk of causing DDIs due to transporter inhibition at the projected $\mathrm{C}_{\text {eff }}$ (Table S6) The plasma protein binding of PF-07304814 was measured across species using equilibrium dialysis showing moderate binding to plasma proteins with plasma free fractions of 0.18 to 0.38 across species (Table S7). 
Encouraging human PK predictions for PF-00835231 formation

The predicted human plasma clearance of PF-07304814 is $\sim 10 \mathrm{~mL} / \mathrm{min} / \mathrm{kg}$ based on scaling in vitro human liver S9 CLint data (using equations 9 and 10, see Methods) and represents a conservative prediction of total $\mathrm{Cl}_{\mathrm{p}}$ as it only accounts for conversion of prodrug to active moiety in the liver. The human $\mathrm{Vd}_{\mathrm{ss}}$ for $\mathrm{PF}-07304814$ is predicted to be $\sim 0.1 \mathrm{~L} / \mathrm{kg}$ based on its acidic physiochemistry and observed human $\mathrm{Vd}_{\mathrm{ss}}$ values of other phosphate prodrugs ${ }^{31,32}$. Based on the predicted $\mathrm{Cl}_{\mathrm{p}}, \mathrm{Vd}_{\mathrm{ss}}$, and a $\sim 75 \%$ conversion to PF-00835231 based on the mean conversion in animals, PF-07304814 is anticipated to exhibit a short half-life of $\sim 0.1$ hour with high conversion to the active moiety (Fig. 6B).

\section{$\underline{\text { PF-07304814 unlikely to contribute to antiviral activity in vivo }}$}

In a direct comparison, using the same SARS-Cov-2 3CLpro assay method as described in ${ }^{16}$, the prodrug PF-07304814 binds and inhibits SARS-CoV-2 3CLpro activity with a Ki of 174nM providing a >600-fold less potent $\mathrm{Ki}$ in comparison to the active moiety $\mathrm{PF}-00835231$ $(0.27 \mathrm{nM})^{16}$. However, PF-07304814 shows apparently similar antiviral activity to PF-00835231 (1-12-fold, Fig. 2A) across cellular in vitro assays. This is most likely due to the partial conversion of PF-07304814 to PF-00835231 in the cellular assays by alkaline phosphatase. This was consistent with PF-00835231 concentrations measured at approximately $50 \%$ of the PF07304814 starting concentration at the end of the 3-day incubation in the VeroE6 cell assay. It is not believed that PF-07304814 has antiviral activity without first converting to PF-00835231. 
$\underline{\text { PF-07304814 dose projection provides clinical flexibility to achieve target } \mathrm{C}_{\text {eff }}}$

The antiviral activity and projected exposure for PF-00835231 after conversion from PF07304814 in vivo was used to derive the minimal $\mathrm{C}_{\text {eff }}$ and dose estimates. Based on the predicted human PK and $75 \%$ conversion of the prodrug, a free plasma concentration of the active moiety PF-00835231 of $0.5 \mu \mathrm{M}\left(\mathrm{C}_{\text {eff }}\right)$ can be achieved with a $500 \mathrm{mg}$ continuous IV infusion of the prodrug over 24 hours (Fig. 6C). The estimated time to achieve 90\% steady state exposure of PF00835231 is approximately 6 hours. Due to the improved solubility (>200mg/mL), the dose of PF-0730814 can be delivered in a volume of less than $0.25 \mathrm{~L}$. In addition the dose can be increased if the observed human plasma $\mathrm{Cl}$ exceeds $6 \mathrm{~mL} / \mathrm{min} / \mathrm{kg}$, if the percent converted from prodrug to active is less than predicted, or if exposures in excess of the minimal $\mathrm{C}_{\text {eff }}(0.5 \mu \mathrm{M}$ free) are required to maximize clinical activity (Fig. 5B). Overall, the improved solubility of PF07304814 would theoretically enable $>100$-fold the proposed minimal $\mathrm{C}_{\text {eff }}$ dose in a $0.25 \mathrm{~L}$ dose volume.

Preclinical safety profile supports progression to clinical evaluation

A toxicology assessment consisting of an in vitro battery of genetic toxicity, secondary and safety pharmacology studies, in conjunction with a single species (rat) in vivo Good Laboratory Practice (GLP) study has been completed.

The safety profiles of PF-07304814 and PF-00835231 were assessed individually in a range of in vitro and in vivo safety studies in rats. In the in vitro studies, PF-07304814 and PF-00835231 were negative in the bacterial reverse mutation assay and did not induce micronuclei formation. Both compounds had minimal potential for secondary (off-target) pharmacology at clinically 
relevant exposures. Neither PF-07304814 nor PF-00835231 inhibited hERG current amplitude at up to $300 \mu \mathrm{M}(1,770$ - and 600-fold, respectively, in reference to the projected unbound human $\mathrm{C}_{\max }$ of 0.17 and $0.50 \mu \mathrm{M}$, respectively, at the projected human efficacious dose), indicating a favorable cardiovascular safety profile. In human blood hemocompatibility assays, both compounds had no effect on hemolysis or flocculation/turbidity parameters, indicating compatibility with human blood and supporting intravenous administration.

PF-07304814 was administered to rats via continuous IV infusion for 24 hours in a GLP study. There was no test article related findings and no target organ toxicity was identified. PF07304814 had no effects on neurological safety pharmacology parameters as assessed by functional observation battery in the 24-hour continuous IV infusion rat study. The no observed adverse effect level (NOAEL) was $1000 \mathrm{mg} / \mathrm{kg}$. PF-00835231 was also administered to male rats via continuous IV infusion for 4 days in a non-GLP exploratory toxicity study and was tolerated at $246 \mathrm{mg} / \mathrm{kg} / \mathrm{day}$, the highest feasible dose tested. PF-00835231-related findings in this study were limited to minimal, non-adverse effects on clinical chemistry parameters including higher mean triglycerides (1.9-3.6x vs controls), cholesterol (1.3x), and phosphorus (1.1x) without any microscopic correlates or associated functional changes. No test article related adverse effects were seen in any study.

At the NOAEL from the 24-hour, GLP continuous IV infusion study with PF-07304814 in rats, the anticipated exposure margins for unbound $\mathrm{C}_{\max }$ and $\mathrm{AUC}_{24}$ are 97 and 65-fold for PF07304814 and 25 and 21-fold for PF-00835231, at the projected minimum human efficacious dose of 500mg/day. This indicates the potential to safely evaluate multiples over $\mathrm{EC}_{90}$ in humans 
during clinical testing to understand the exposure response relationship and to achieve high levels of inhibition, if required. Furthermore, no overlapping or additive toxicity with medications currently being used in standard of care COVID-19 treatment is expected with administration of PF-07304814 in humans, making PF-07304814 an attractive combination partner. Based on results from the set of safety studies conducted, PF-07304814 exhibited an encouraging nonclinical safety profile and supported progression into Phase 1 clinical studies.

\section{Conclusions}

PF-07304814 is a phosphate prodrug that is rapidly converted in vivo to the active moiety, PF00835231, which exhibits high selectivity over human proteases, acts as a broad-spectrum coronavirus 3CL protease inhibitor, and demonstrates potent antiviral activity in vivo. Robust antiviral activity was demonstrated in a range of cellular in vitro assays in keeping with SARSCOV-2 human airway epithelial data ${ }^{22}$ suggesting a $\mathrm{C}_{\text {eff }}$ value of $\sim 0.5 \mu \mathrm{M}$ unbound. This Ceff exposure was consistent with the free plasma concentration associated with the maximal viral load decrease in the in vivo mouse SARS-CoV model. The predicted human pharmacokinetics of PF-07304814 provide the ability to achieve systemic unbound concentrations of $0.5 \mu \mathrm{M}\left(\mathrm{EC}_{90}\right)$ of PF-00835231 by delivering 500mg as a continuous infusion over 24 hours with infusion volumes of less than $0.25 \mathrm{~L}$. In addition, higher doses (up to and beyond $10 \mathrm{x} \mathrm{C}_{\text {eff }}$ ) also remain feasible due to the high solubility of PF-07304814.

Overall, PF-07304814 exhibits an encouraging preclinical profile that has the ADME, safety, and once converted to PF-00835231, SARS-CoV-2 antiviral activity to support progression to the clinic as a novel COVID-19 single agent antiviral treatment, with potential for further additional 
benefit in combination with antivirals that target other critical stages of the coronavirus life cycle. The favorable profile of PF-07304814 warrants clinical evaluation and is currently in clinical trials: NCT04627532 and NCT04535167.

\section{References and Notes}

1. Zhou, P. et al. A pneumonia outbreak associated with a new coronavirus of probable bat origin. Nature 579, $270-273$ (2020).

2. Sahin, A. R. 2019 Novel Coronavirus (COVID-19) Outbreak: A Review of the Current Literature. Eurasian J. Med. Oncol. (2020) doi:10.14744/ejmo.2020.12220.

3. WHO Coronavirus Disease (COVID-19) Dashboard. https://covid19.who.int.

4. Coronavirus (Covid-19) Update: FDA Issues Emergency Use Authorization for Potential Covid-19 Treatment. https://www.fda.gov/news-events/press-announcements/coronavirus-covid-19-update-fda-issues-emergencyuse-authorization-potential-covid-19-treatment (2020).

5. Beigel, J. H. et al. Remdesivir for the Treatment of Covid-19 - Preliminary Report. N. Engl. J. Med. (2020) doi:10.1056/NEJMoa2007764.

6. Commissioner, O. of the. FDA Approves First Treatment for COVID-19. FDA https://www.fda.gov/newsevents/press-announcements/fda-approves-first-treatment-covid-19 (2020).

7. Commissioner, O. of the. Coronavirus (COVID-19) Update: FDA Authorizes Monoclonal Antibody for Treatment of COVID-19. FDA https://www.fda.gov/news-events/press-announcements/coronavirus-covid-19update-fda-authorizes-monoclonal-antibody-treatment-covid-19 (2020).

8. Kim, J. C., Spence, R. A., Currier, P. F., Lu, X. \& Denison, M. R. Coronavirus protein processing and RNA synthesis is inhibited by the cysteine proteinase inhibitor E64d. Virology 208, 1-8 (1995).

9. Stobart, C. C., Lee, A. S., Lu, X. \& Denison, M. R. Temperature-sensitive mutants and revertants in the coronavirus nonstructural protein 5 protease (3CLpro) define residues involved in long-distance communication and regulation of protease activity. J. Virol. 86, 4801-4810 (2012).

10. Hegyi, A. \& Ziebuhr, J. Conservation of substrate specificities among coronavirus main proteases. J. Gen. Virol. 83, 595-599 (2002). 
11. Anand, K., Ziebuhr, J., Wadhwani, P., Mesters, J. R. \& Hilgenfeld, R. Coronavirus Main Proteinase (3CLpro) Structure: Basis for Design of Anti-SARS Drugs. Science 300, 1763-1767 (2003).

12. Bacon, B. R. et al. Boceprevir for Previously Treated Chronic HCV Genotype 1 Infection. N. Engl. J. Med. 364, 1207-1217 (2011).

13. Chary, A. \& Holodniy, M. Recent Advances in Hepatitis C Virus Treatment: Review of HCV Protease Inhibitor Clinical Trials. Rev. Recent Clin. Trials 5, 158-173 (2010).

14. Hoetelmans, R. M. W. et al. Clinical pharmacology of HIV protease inhibitors: focus on saquinavir, indinavir, and ritonavir. Pharm. World Sci. 19, 159-175 (1997).

15. Pillaiyar, T., Manickam, M., Namasivayam, V., Hayashi, Y. \& Jung, S.-H. An Overview of Severe Acute Respiratory Syndrome-Coronavirus (SARS-CoV) 3CL Protease Inhibitors: Peptidomimetics and Small Molecule Chemotherapy. J. Med. Chem. 59, 6595-6628 (2016).

16. Hoffman, R. L. et al. Discovery of Ketone-Based Covalent Inhibitors of Coronavirus 3CL Proteases for the Potential Therapeutic Treatment of COVID-19. J. Med. Chem. 63, 12725-12747 (2020).

17. Rota, P. A. et al. Characterization of a Novel Coronavirus Associated with Severe Acute Respiratory Syndrome. Science 300, 1394-1399 (2003).

18. Marra, M. A. et al. The Genome Sequence of the SARS-Associated Coronavirus. Science 300, 1399-1404 (2003).

19. Zhang, L. et al. Crystal structure of SARS-CoV-2 main protease provides a basis for design of improved $\alpha$ ketoamide inhibitors. Science 368, 409-412 (2020).

20. Kalgutkar, A. S. et al. N-(3,4-dimethoxyphenethyl)-4-(6,7-dimethoxy-3,4-dihydroisoquinolin-2[1H]-yl)-6,7dimethoxyquinazolin-2-amine (CP-100,356) as a 'chemical knock-out equivalent' to assess the impact of efflux transporters on oral drug absorption in the rat. J. Pharm. Sci. 98, 4914-4927 (2009).

21. Shen, L. et al. Dose-response curve slope sets class-specific limits on inhibitory potential of anti-HIV drugs. Nat. Med. 14, 762-766 (2008).

22. Vries, M. de et al. Comparative study of a 3CLpro inhibitor and remdesivir against both major SARS-CoV-2 clades in human airway models. bioRxiv 2020.08.28.272880 (2020) doi:10.1101/2020.08.28.272880. 
23. Erb, P., Battegay, M., Zimmerli, W., Rickenbach, M. \& Egger, M. Effect of Antiretroviral Therapy on Viral Load, CD4 Cell Count, and Progression to Acquired Immunodeficiency Syndrome in a Community Human Immunodeficiency Virus-Infected Cohort. Arch. Intern. Med. 160, 1134-1140 (2000).

24. Bakowski, M. A. et al. Oral drug repositioning candidates and synergistic remdesivir combinations for the prophylaxis and treatment of COVID-19. bioRxiv 2020.06.16.153403 (2020) doi:10.1101/2020.06.16.153403.

25. Koizumi, Y. et al. Quantifying antiviral activity optimizes drug combinations against hepatitis $\mathrm{C}$ virus infection. Proc. Natl. Acad. Sci. U. S. A. 114, 1922-1927 (2017).

26. Roberts, A. et al. A mouse-adapted SARS-coronavirus causes disease and mortality in BALB/c mice. PLoS Pathog. 3, e5 (2007).

27. Frieman, M. et al. Molecular Determinants of Severe Acute Respiratory Syndrome Coronavirus Pathogenesis and Virulence in Young and Aged Mouse Models of Human Disease. J. Virol. 86, 884-897 (2012).

28. Di, L. et al. Development of a new permeability assay using low-efflux MDCKII cells. J. Pharm. Sci. 100, 4974-4985 (2011).

29. Varma, M. V. et al. pH-Dependent solubility and permeability criteria for provisional biopharmaceutics classification (BCS and BDDCS) in early drug discovery. Mol. Pharm. 9, 1199-1212 (2012).

30. Reddy, M. B. et al. Pharmacokinetic/Pharmacodynamic Predictors of Clinical Potency for Hepatitis C Virus Nonnucleoside Polymerase and Protease Inhibitors. Antimicrob. Agents Chemother. 56, 3144-3156 (2012).

31. Sobue, S., Tan, K., Layton, G., Eve, M. \& Sanderson, J. B. Pharmacokinetics of fosfluconazole and fluconazole following multiple intravenous administration of fosfluconazole in healthy male volunteers. Br. J. Clin.

Pharmacol. 58, 20-25 (2004).

32. Stella, V. J. A case for prodrugs: Fosphenytoin. Adv. Drug Deliv. Rev. 19, 311-330 (1996).

33. Uhlén, M. et al. Tissue-based map of the human proteome. Science 347, (2015).

34. Aoyama, T. et al. Pharmacokinetics of Fluconazole and Fosfluconazole after Intraperitoneal Administration to Peritoneal Dialysis Rats. Drug Metab. Pharmacokinet. 20, 485-490 (2005).

35. Broad-spectrum inhibition of coronavirus main and papain-like proteases by HCV drugs. (2020) doi:10.21203/rs.3.rs-26344/v1.

36. Ghosh, A. K. et al. Design and Synthesis of Peptidomimetic Severe Acute Respiratory Syndrome Chymotrypsin-like Protease Inhibitors. J. Med. Chem. 48, 6767-6771 (2005). 
37. Grum-Tokars, V., Ratia, K., Begaye, A., Baker, S. C. \& Mesecar, A. D. Evaluating the 3C-like protease activity of SARS-Coronavirus: Recommendations for standardized assays for drug discovery. Virus Res. 133, 63-73 (2008).

38. Tomar, S. et al. Ligand-induced Dimerization of Middle East Respiratory Syndrome (MERS) Coronavirus nsp5 Protease (3CLpro): IMPLICATIONS FOR nsp5 REGULATION AND THE DEVELOPMENT OF ANTIVIRALS. J. Biol. Chem. 290, 19403-19422 (2015).

39. St John, S. E., Tomar, S., Stauffer, S. R. \& Mesecar, A. D. Targeting zoonotic viruses: Structure-based inhibition of the 3C-like protease from bat coronavirus HKU4--The likely reservoir host to the human coronavirus that causes Middle East Respiratory Syndrome (MERS). Bioorg. Med. Chem. 23, 6036-6048 (2015).

40. Agnihothram, S. et al. A mouse model for Betacoronavirus subgroup $2 \mathrm{c}$ using a bat coronavirus strain HKU5 variant. mBio 5, e00047-00014 (2014).

41. St John, S. E. et al. X-ray structure and inhibition of the feline infectious peritonitis virus 3C-like protease: Structural implications for drug design. Bioorg. Med. Chem. Lett. 25, 5072-5077 (2015).

42. St John, S. E., Anson, B. J. \& Mesecar, A. D. X-Ray Structure and Inhibition of 3C-like Protease from Porcine Epidemic Diarrhea Virus. Sci. Rep. 6, 25961 (2016).

43. Deng, X. et al. Coronaviruses resistant to a 3C-like protease inhibitor are attenuated for replication and pathogenesis, revealing a low genetic barrier but high fitness cost of resistance. J. Virol. 88, 11886-11898 (2014).

44. Tomar, S. Understanding the determinants for substrate recognition, regulation of enzymatic activity and the development of broad-spectrum inhibitors of coronavirus 3-chymotrypsin-like proteases. (2015).

45. Yen, Y.-C. et al. Development of an Efficient Enzyme Production and Structure-Based Discovery Platform for BACE1 Inhibitors. Biochemistry 58, 4424-4435 (2019).

46. Ianevski, A., He, L., Aittokallio, T. \& Tang, J. SynergyFinder: a web application for analyzing drug combination dose-response matrix data. Bioinforma. Oxf. Engl. 33, 2413-2415 (2017).

47. Stopher, D. \& McClean, S. An improved method for the determination of distribution coefficients. J. Pharm. Pharmacol. 42, 144 (1990). 
48. Szakacs, Z., Haegele, G. \& Tyka, R. 1H/31P NMR pH indicator series to eliminate the glass electrode in NMR spectroscopic pKa determinations. Anal. Chim. Acta 522, 247-258 (2004).

49. Obach, R. S. Prediction of human clearance of twenty-nine drugs from hepatic microsomal intrinsic clearance data: an examination of in vitro half-life approach and nonspecific binding to microsomes. Drug Metab. Dispos. 27, 1350-1359 (1999).

50. Walker, G. S. et al. Biosynthesis of drug metabolites and quantitation using NMR spectroscopy for use in pharmacologic and drug metabolism studies. Drug Metab. Dispos. 42, 1627-1639, 13 pp. (2014).

51. Yates, P., Eng, H., Di, L. \& Obach, R. S. Statistical methods for analysis of time-dependent inhibition of cytochrome P450 enzymes. Drug Metab. Dispos. 40, 2289-2296 (2012).

52. Kalvass, J. C., Maurer, T. S. \& Pollack, G. M. Use of plasma and brain unbound fractions to assess the extent of brain distribution of 34 drugs: comparison of unbound concentration ratios to in vivo P-glycoprotein efflux ratios. Drug Metab. Dispos. 35, 660-666 (2007).

53. Yang, Z. In Vivo Metabolite Kinetics. in Drug Metabolism Handbook 41-64 (John Wiley \& Sons, Ltd, 2008). doi:10.1002/9780470439265.ch4.

54. Jamei, M. et al. The Simcyp Population-based ADME Simulator. Expert Opin. Drug Metab. Toxicol. 5, 211223 (2009).

55. Guidance for Industry Antiviral Product Development - Conducting and Submitting Virology Studies to the Agency. https://www.fda.gov/media/71223/download (2006).

56. Mo, H. et al. Estimation of inhibitory quotient using a comparative equilibrium dialysis assay for prediction of viral response to hepatitis C virus inhibitors. J. Viral Hepat. 18, 338-348 (2011).

57. Duval, X. et al. Amprenavir Inhibitory Quotient and Virological Response in Human Immunodeficiency VirusInfected Patients on an Amprenavir-Containing Salvage Regimen without or with Ritonavir. Antimicrob. Agents Chemother. 46, 570-574 (2002).

58. Shen, L. et al. A Critical Subset Model Provides a Conceptual Basis for the High Antiviral Activity of Major HIV Drugs. Sci. Transl. Med. 3, 91ra63-91ra63 (2011).

59. Green, M. H. L. \& Muriel, W. J. Mutagen testing using TRP+ reversion in Escherichia coli. Mutat. Res. 38, 332 (1976). 
60. Maron, D. M. \& Ames, B. N. Revised methods for the Salmonella mutagenicity test. Mutat. Res. Environ. Mutagen. Relat. Subj. 113, 173-215 (1983).

61. OECD Guideline 471 (Genetic Toxicology: Bacterial Reverse Mutation Test). (21 Jul y1997).

62. Redfern, W. S. et al. Relationships between preclinical cardiac electrophysiology, clinical QT interval prolongation and torsade de pointes for a broad range of drugs: evidence for a provisional safety margin in drug development. Cardiovasc. Res. 58, 32-45 (2003).

63. Brown, A. M. \& Rampe, D. Drug-induced long QT syndrome: is HERG the root of all evil. Pharm. News 7, $15-20(2000)$.

64. Weirich, J. \& Antoni, H. Rate-dependence of antiarrhythmic and proarrhythmic properties of class I and class III antiarrhythmic drugs. Basic Res. Cardiol. 93, 125-132 (1998).

65. Yap, Y. G. \& Camm, A. J. Arrhythmogenic mechanisms of non-sedating antihistamines. Clin. Exp. Allergy 29, 174-181 (1999).

Acknowledgments: The authors would like to thank Sarah Lazzaro, Sumathy Mathialagan, Sangwoo Ryu, Mark West and Emi Yamaguchi (Pfizer) for the transporter inhibition studies. Angela Doran, Chad Limanni, Amanda Plante and Jocelyn Rosado for their in vivo and PK study support (Pfizer). Marcus Ewing (Pfizer) and Gail Johnson (Pfizer) for preformulation studies. Li Hao (Pfizer) for sequence analysis support. Shinji Yamazaki (Pfizer) for PBPK modeling simulations. Daniel Lettiere, Michael Homiski, Michelle Kenyon, Asser Bassyouni, Declan Flynn, William Reagan, Victoria Markiewicz and Stephen Jenkinson for overseeing safety studies, and William Reagan, for expert clinical pathology and pathology support for the toxicology studies. Deli Huang for supplying the HeLa-ACE2 stably transfected cell line.

Funding: A.D.M acknowledges partial support for this project from federal funds from the National Institute of Allergy and Infectious Diseases, National Institutes of Health, Department 
of Health and Human Services, under Contract No. HHSN272201700060C. The content is solely the responsibility of the authors and does not necessarily represent the official views of the National Institutes of Health. The study performed in Dr. Jun Wang's laboratory is partially supported by NIH grant (AI147325) and the Young Investigator Award grant from the Arizona Biomedical Research Centre (ADHS18-198859). Scripps work was supported by a grant from the Bill \& Melinda Gates Foundation \#OPP1107194, and the Scripps Family Impact Fund of the Miramar Charitable Foundation (MCF) MBF is supported by NIH grants R21AI158134, R01 AI148166, R21AI153480, HHSN272201400007C and 75N93019C00051. A DARPA subcontract \#HR0011-20-2-0040, BARDA contract \#ASPR-20-01495, and Bill and Melinda Gates Foundation grants \# INV-006099 and INV-016638.

Author contributions: A.D.M, E.L and B.A contributed to conceptualization, investigation, analysis, visualization and data curation of inhibition of protease activity against a panel of coronavirus 3CLpro experiments. A.D.M contributed to funding acquisition, supervision, project administration and resources of these experiments. J.W and C.M contributed to conceptualization, investigation, analysis, visualization and data curation of the thermal shift experiments. JW contributed to funding acquisition, supervision, project administration and resources of these experiments. M.A.B, T.F.G supervised, designed and carried out antiviral synergy infection experiments. N.B, M.G.K and E.C contributed to the generation of in vitro antiviral synergy data J.B, J.H, Y.Z, L.M.A, L.L,S.N, R.O, C.S, R.K, R.H and B.B contributed to the analysis, interpretation of protease and antiviral data from collaborators and internal data. E.K designed and interpreted the ADME transporter experiments, R.S.O, H.E, R.M.J, E.P.K contributed to the metabolism, pharmacokinetics and bioanalysis of PF-07304814 and PF00835231. J.R.L, S.A.L, M.N.O., and M.T. designed and interpreted formulation experiments 
and characterization of API properties. M.R.R, M.P, K.O, R.H and D.O designed and synthesized PF-07304814. R.M.J, B.B, R.S.O and E.K contributed to the conceptualization, analysis and calculations for the prediction of human PK and dose estimate for PF-07304814. J.G.S, L.W.U, R.M.J contributed to the design, supervision and interpretation of in vitro and in vivo safety study data. C.A, A.A, M.I.R contributed to the scientific discussion, experimental design, data interpretation in addition to manuscript review and editing. N.S. contributed to the analysis, interpretation of protease and antiviral data. S.W.M. and M.B.F. designed and interpreted and H.H., J.L., M.M., R.H., R.E.H., S.W. executed the in vivo animal efficacy studies. All authors contributed to writing drafts of the manuscript. Competing interests: A.D.M has a sponsored program contract with Pfizer to test compounds for inhibition of coronavirus proteases. JW has a sponsored research agreement with Pfizer to test compounds for inhibition of coronavirus proteases. The Frieman Laboratory was funded by Pfizer for the work in this manuscript. Data and materials availability: All data are available in the main text or the supplementary materials.

\section{List of Supplementary Materials}

Materials and Methods

Figures S1-S2

Tables S1-S11

References (35-65) 
Table 1. Activity of PF-00835231 against 3CLpro of coronaviruses

\begin{tabular}{lc}
\hline Virus & $\mathbf{K}_{\mathbf{i}}(\mathbf{n M})$ \\
\hline NL63-CoV & Alpha-CoV \\
HCoV-229E & $0.77 \pm 0.52$ \\
PEDV & $1.5 \pm 0.76$ \\
FIPV & $0.30 \pm 0.11$ \\
\multicolumn{1}{c}{ Beta-CoV } \\
SARS-CoV-2* & $0.27 \pm 0.1$ \\
HKU1-CoV & $0.85 \pm 0.24$ \\
HKU4-CoV & $0.034 \pm 0.079$ \\
HKU5-CoV & $0.033 \pm 0.12$ \\
HKU9-CoV & $0.74 \pm 0.68$ \\
MHV-CoV & $1.2 \pm 0.90$ \\
OC43-CoV & $0.51 \pm 0.12$ \\
& Gamma-CoV \\
IBV-CoV & $4.0 \pm 0.37$ \\
\hline
\end{tabular}

*Data reported in ${ }^{16}$ 


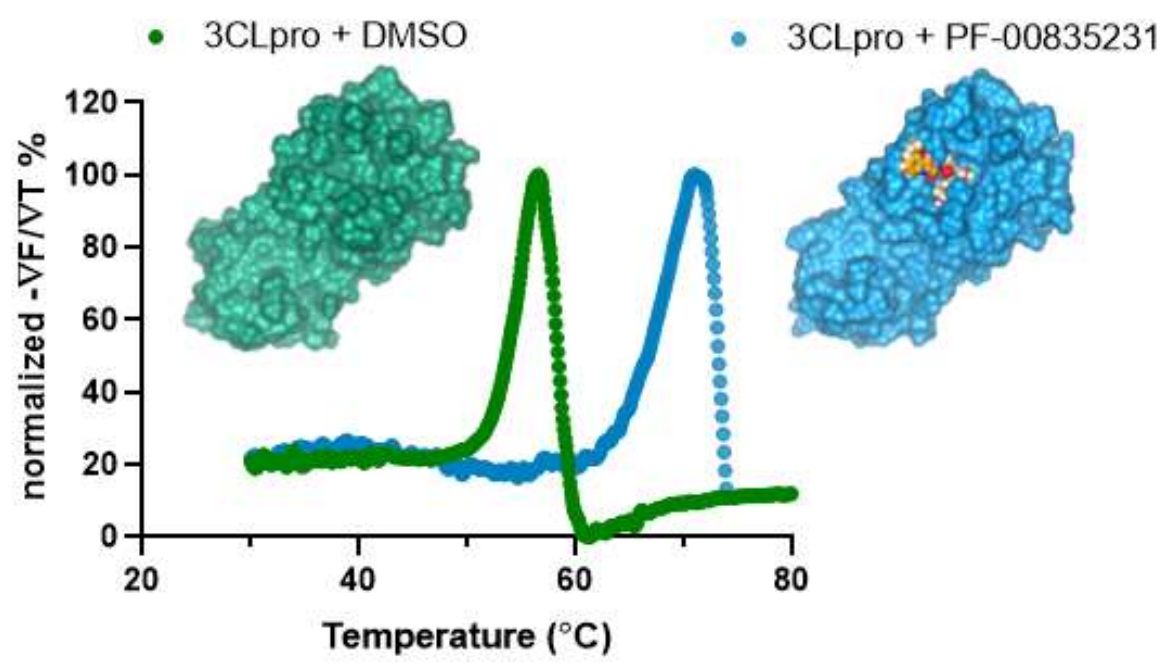

Fig. 1. Representative thermal shift binding data of PF-00835231 with SARS-CoV-2

3CLpro. X-ray structures of SARS CoV-2 3CLpro apoenzyme (left) and SARS CoV-2 3CLpro in complex with PF-00835231 (right). 


\begin{tabular}{|c|c|c|c|c|c|c|}
\hline \multirow[b]{2}{*}{ Cels } & \multirow[b]{2}{*}{ Virus } & \multirow{2}{*}{$\begin{array}{l}\text { P-gp } \\
\text { Entikg } \\
\text { intibtor }\end{array}$} & \multicolumn{2}{|c|}{ PF-00835231 } & \multicolumn{2}{|c|}{ PF-07304814 } \\
\hline & & & $\begin{array}{c}\mathrm{EC}_{\mathrm{s0}} \mu \mathrm{M} \\
\text { GeoMtean }(95 \%) \mathrm{Cl})\end{array}$ & $\begin{array}{c}\mathrm{CC}_{36} \mu \mathrm{M} \\
\text { Geollean }(95 \% \mathrm{Cl})\end{array}$ & $\begin{array}{c}\mathrm{EC}_{x} / \mathrm{M} \\
\text { GeolMean }(96 \% \mathrm{Cl})\end{array}$ & $\begin{array}{c}\mathrm{CC}_{\mathrm{s0}} \boldsymbol{\mu M} \\
\text { Geomean }(95 \% \mathrm{Cl})\end{array}$ \\
\hline \multirow{3}{*}{$\begin{array}{c}\text { Vero E6-enACE2 } \\
\text { (kidney) }\end{array}$} & \multirow{3}{*}{$\begin{array}{c}\text { SARS2 } \\
\text { Washington } 1\end{array}$} & 0 & $\begin{array}{c}40(30,53) \\
n=10\end{array}$ & $\begin{array}{c}2100(\mathrm{ND}) \\
n=9\end{array}$ & $\begin{array}{c}87(71,110) \\
n=10\end{array}$ & $\begin{array}{c}>100(\mathrm{ND}) \\
n=8\end{array}$ \\
\hline & & $05 \mu \mathrm{m}$ & $\begin{array}{c}30(1,1,7.7) \\
n=7\end{array}$ & $\begin{array}{c}>100 \text { (ND) } \\
n=6\end{array}$ & $\begin{array}{c}27(7.6,94) \\
n=7\end{array}$ & $\begin{array}{c}>100 \text { (ND) } \\
n=7\end{array}$ \\
\hline & & $2 \mu m$ & $\begin{array}{c}0.24(0.14,0.41) \\
n=6\end{array}$ & $\begin{array}{c}>100(N D) \\
n=6\end{array}$ & $\begin{array}{c}38(1.6 .88) \\
n=7\end{array}$ & $\begin{array}{c}>100(\mathrm{ND}) \\
n=6\end{array}$ \\
\hline \multirow{3}{*}{$\begin{array}{l}\text { VeroE6-EGFP } \\
\text { (kodney) }\end{array}$} & \multirow{3}{*}{$\begin{array}{l}\text { SARS2 BetaCov } \\
\text { GHB-03021/2020 }\end{array}$} & 0 & $\begin{array}{c}89(77,100) \\
n=5\end{array}$ & $\begin{array}{c}>100(\mathrm{ND}) \\
n=8\end{array}$ & $\begin{array}{c}\times 50(N D) \\
n=4\end{array}$ & $\begin{array}{c}>50 \text { (ND) } \\
n=4\end{array}$ \\
\hline & & $0.5 . \mu \mathrm{m}$ & $\begin{array}{c}B .2(3.1,22) \\
n=B\end{array}$ & $\begin{array}{c}>100(\mathrm{ND}) \\
n=8\end{array}$ & $\begin{array}{c}27(6.3,120) \\
n=2\end{array}$ & $\begin{array}{c}>50 \text { (ND) } \\
\text { nu4 }\end{array}$ \\
\hline & & $2 \mathrm{um}$ & $\begin{array}{c}0.76(0,45,1,3) \\
n=4\end{array}$ & $\begin{array}{c}>50(N D) \\
n=4\end{array}$ & $\begin{array}{c}0.83(0.50,1.4) \\
n=3\end{array}$ & $\begin{array}{c}>50 \text { (ND) } \\
n=4\end{array}$ \\
\hline \multirow{2}{*}{$\begin{array}{l}\text { MRC-5 } \\
\text { (tung) }\end{array}$} & \multirow{2}{*}{$\mathrm{HCOV}-22 \mathrm{gE}$} & 0 & $\begin{array}{c}0.069(0.056,0.085) \\
n=7\end{array}$ & $\begin{array}{l}>100 \\
n=5\end{array}$ & $\begin{array}{c}0.074\{0.013,0.42) \\
n=3\end{array}$ & $\begin{array}{l}>100 \\
n=3\end{array}$ \\
\hline & & $0.5 \mu \mathrm{m}$ & $\begin{array}{c}0.080(0.017 .037) \\
n=3\end{array}$ & $\begin{array}{l}100 \\
n=3\end{array}$ & $\begin{array}{c}0.058(0.023,0.15) \\
n=3\end{array}$ & $\begin{array}{l}>100 \\
n=3\end{array}$ \\
\hline
\end{tabular}

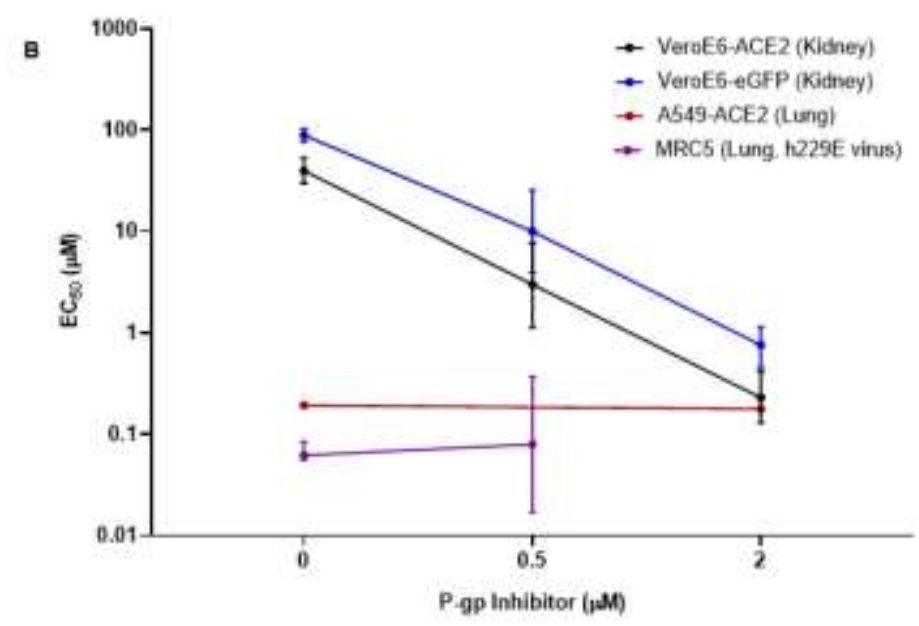

Fig. 2. Antiviral activity across cell lines and viruses. (A) In vitro antiviral activity, and cytotoxicity for PF-00835231 and PF-07304814 with and without the P-gp efflux inhibitor, CP100356. (B) EC50 values with PF-00835231 with increasing P-gp inhibitor in human lung and monkey kidney cell lines. A549-ACE2 human lung carcinoma data (red) as reported in ${ }^{22}$. 
A

Viral Inhibition with combinations PF-00835231 and Remdesivir

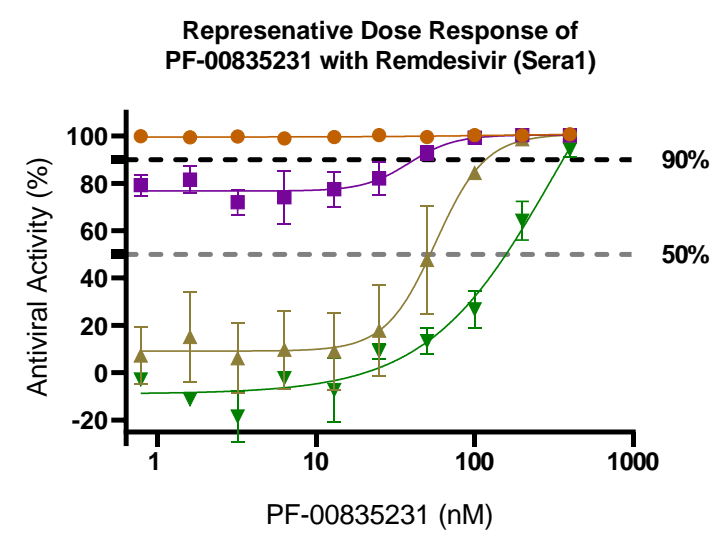

Change in PF-00835231 Viral Inhibition with Remdesivir

\begin{tabular}{|c|c|c|}
\hline $\begin{array}{c}\text { Remdesivir } \\
\text { (nM) }\end{array}$ & $\begin{array}{c}\text { PF-00835231 conc. } \\
\text { for 50\% antiviral activity } \\
(\mathrm{nM}, \mathrm{n}=2)\end{array}$ & $\begin{array}{c}\text { PF-00835231 conc. } \\
\text { for 90\% antiviral activity } \\
(\mathrm{nM}, \mathrm{n}=2)\end{array}$ \\
\hline 0 & $134(143,125)$ & $433(466,265)$ \\
\hline 48 & $62.8(66.2,59.4)$ & $123(31.4-1082)$ \\
\hline 95 & $<0.078$ & $54.5(41.7,67.2)$ \\
\hline 190 & $<0.078$ & $<0.078$ \\
\hline
\end{tabular}

B Combination effect of PF-00835231 and Remdesivir

Representative Synergy Landscape (Sera 1)

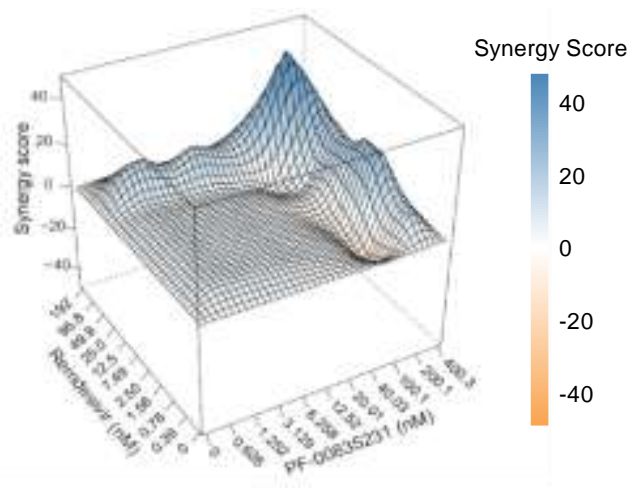

Synergy Scores

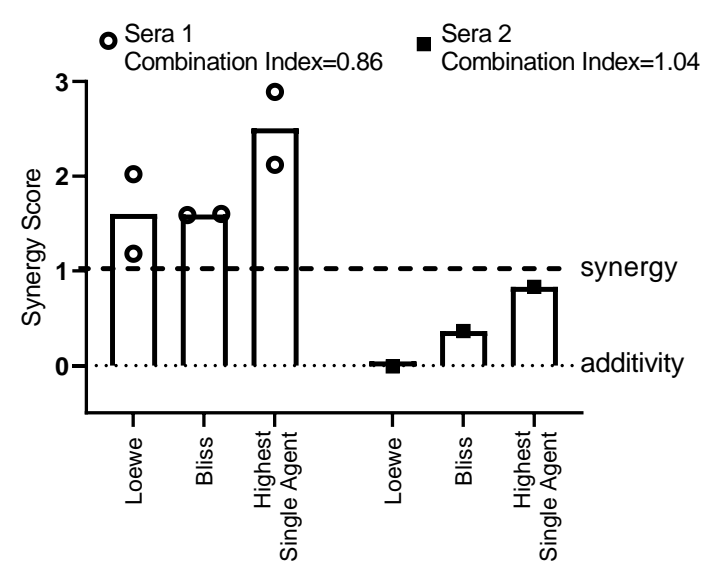

Fig. 3. Measuring potential synergy between PF-00835231 and remdesivir in HeLa-ACE2

cells. (A) (Top) Representative antiviral dose response curves of PF-00835231 in combination with remdesivir against SARS-CoV-2. Serial dilutions of PF-00835231 with a range of fixed concentration of remdesivir. (Bottom) In vitro absolute antiviral activity shift in 50\% and 90\% antiviral activity with fixed concentrations of remdesivir. (B) (Top) A representative 3dimensional drug interaction landscape plotting synergy scores analyzed using Synergyfinder (median scores of 3 replicates). (Bottom) Average in vitro combination synergy scores from the 3 experiments using 2 different patients' sera (shown separately). 

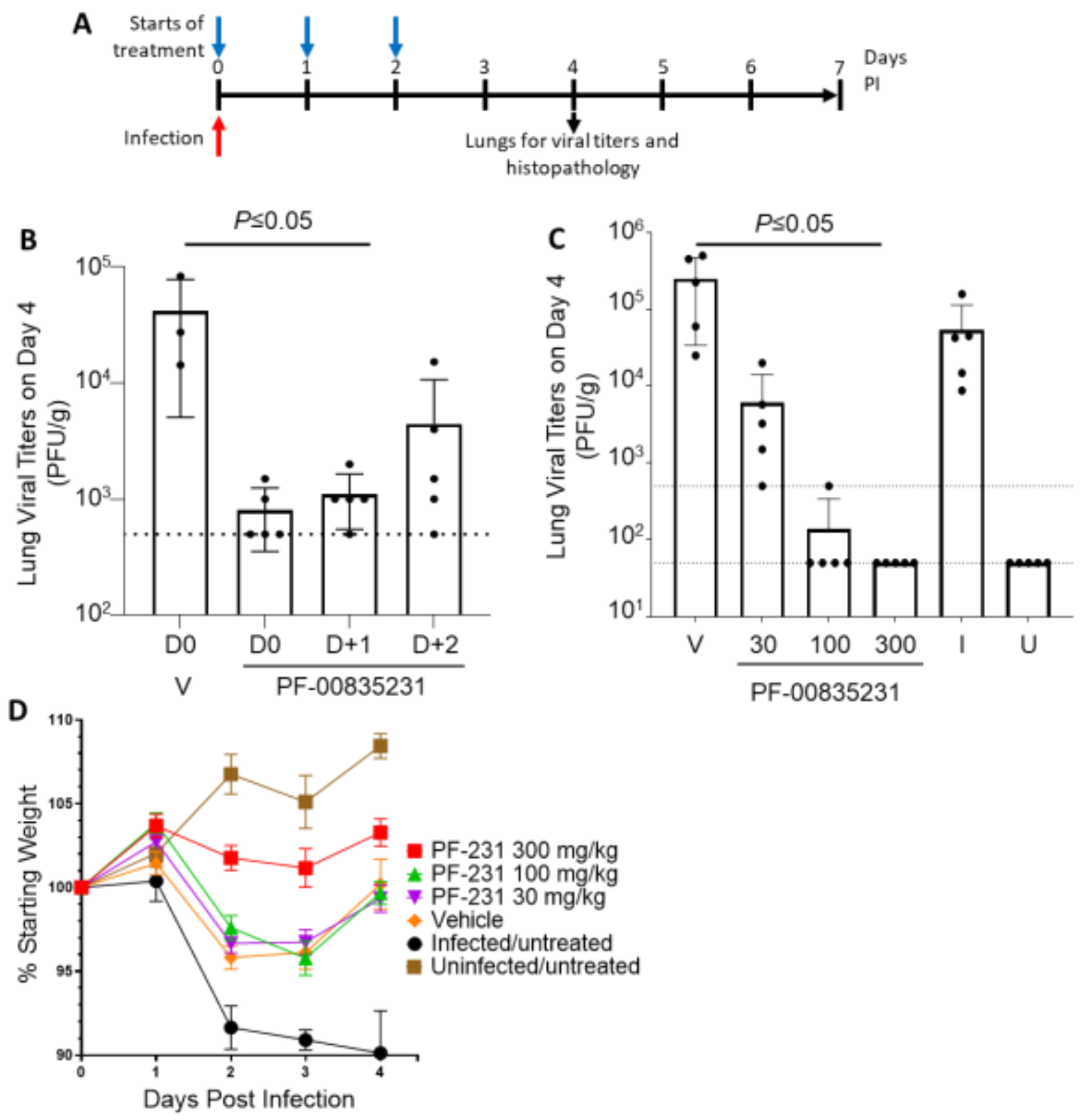


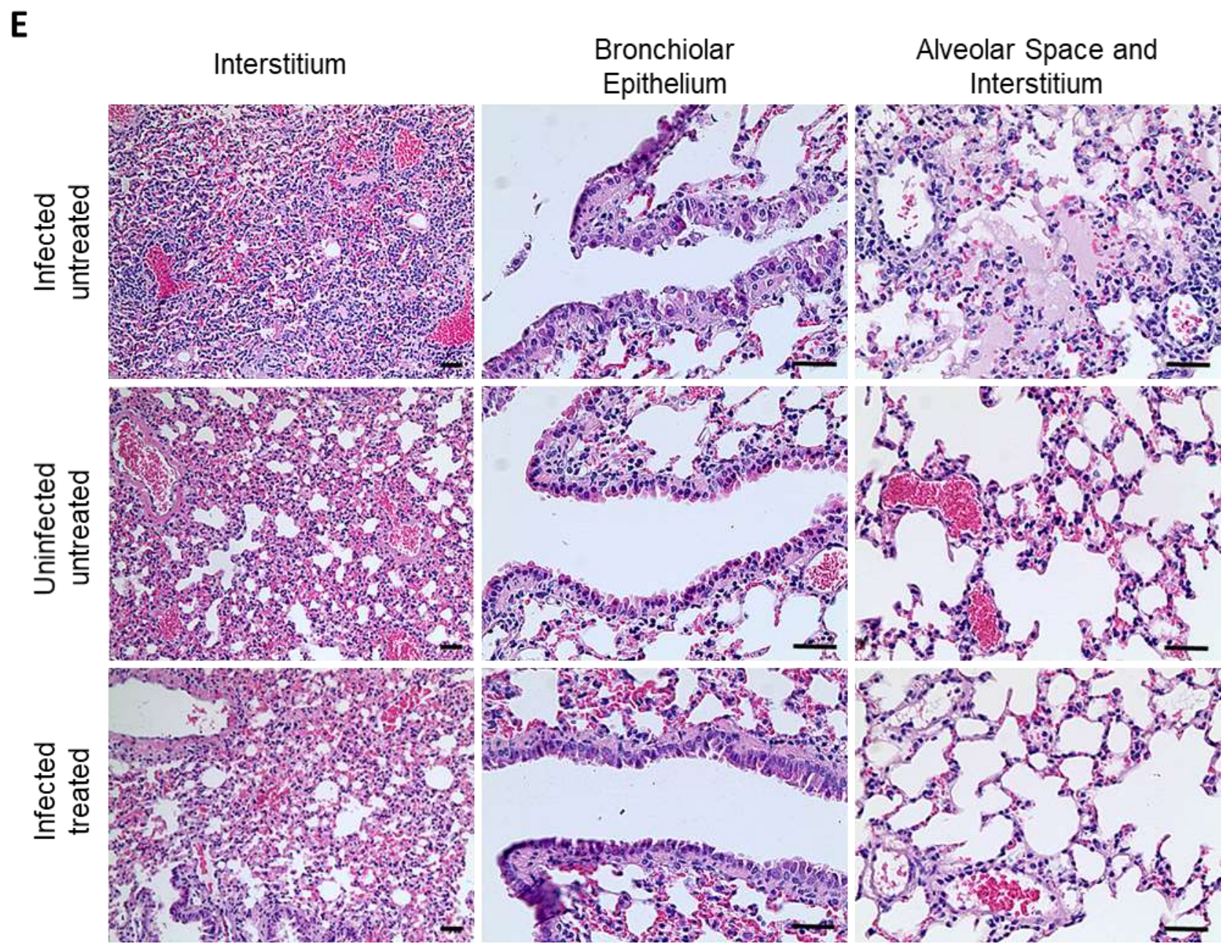

Fig. 4. In vivo activity of PF-00835231 in a mouse model of SARS-CoV infection. A. Study design for in vivo experiments. Infection with SARS-CoV-MA15 was always on day 0. Treatment began on day 0 (panel C) or day 0 , day 1 , or day 2 post-infection (panel B). Lungs were harvested on day 4 post-infection for viral titers and lung histopathology (n=5). B. Lung viral titers for PF-00835231-treated (100 mg/kg, S.C. BID) mice when treatment was started on day 0 or delayed to day 1 and day 2 post-infection. C. Lung viral titers for mice treated in a dose-response of PF-00835231 at 30, 100, $300 \mathrm{mg} / \mathrm{kg}$, S.C. BID starting on day 0. D. Change in body weight of the mice from the experiment shown in panel C. E. Representative photomicrographs of lung sections stained with 
hematoxylin and eosin. Lungs from infected/untreated mice (top row) displayed perivascular and interstitial inflammation (top, left), degeneration and desquamation of the bronchiolar epithelium (top, middle) and proteinaceous exudate in the alveolar space with interstitial inflammatory cells (top, right), all of which were not observed in uninfected/untreated mice (middle row), and in the infected mice treated with PF00835231 at $300 \mathrm{mg} / \mathrm{kg}$ (bottom row). The scale bars represent $50 \mu \mathrm{m}$. LOD, limit of detection; I, infected, untreated; LOQ, limit of quantification; U, uninfected; V, vehicletreated; Viral Titers error bars represent standard deviation; Weight change error bars represent SEM. 
A<smiles>COc1cccc2[nH]c(C(=O)N[C@@H](CC(C)C)C(=O)N[C@@H](C[C@H]3CCNC3=O)C(=O)COP(=O)(O)O)cc12</smiles>

PF-07304814

(Prodrug)

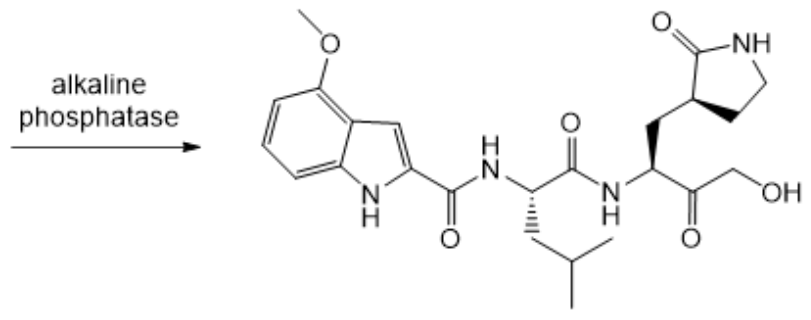

PF-00835231

(Active Moiety)

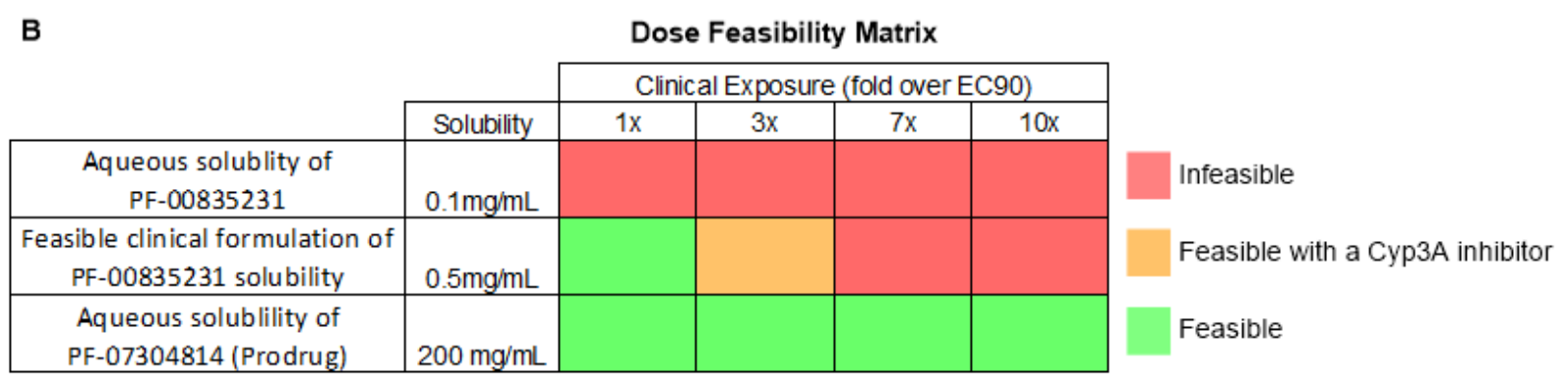

Fig. 5. PF-7304814 prodrug and PF-00835231 structures and dose considerations. (A)

Chemical structure of conversion of prodrug PF-07304814 to the active moiety PF-00835231 by alkaline phosphatase. (B) Dose feasibility matrix illustrating the ability to achieve higher target exposures with increasing solubility and the limitations of dosing PF-00835231. with dosing either aqueous PF-00835231, clinically formulated PF-00835231, or aqueous PF-07304814 (prodrug). The infeasible limit (red) is assumed to be $1 \mathrm{~L}$ per day with a $2 \mathrm{x}$ potential benefit with a Cyp inhibitor (orange). Any dose under that is considered feasible (green). 

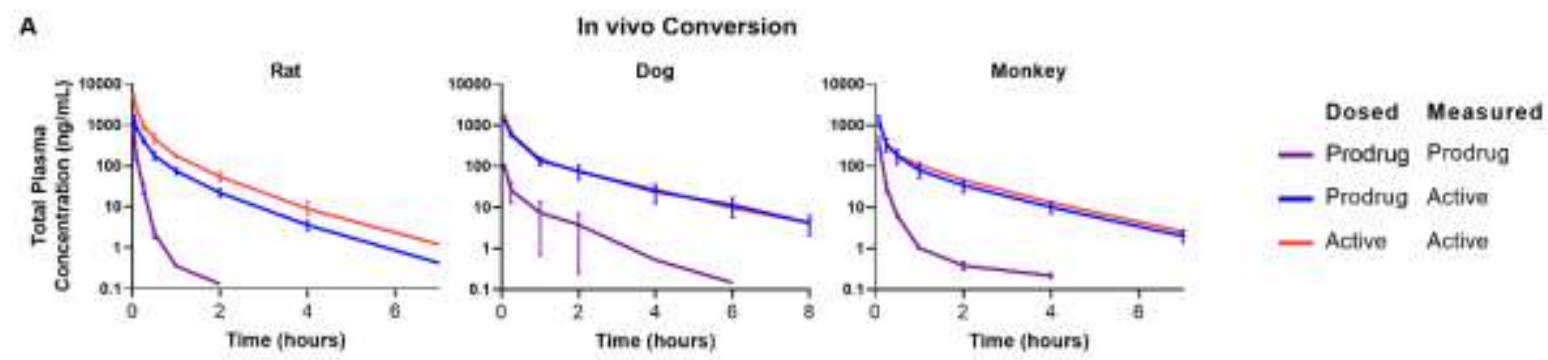

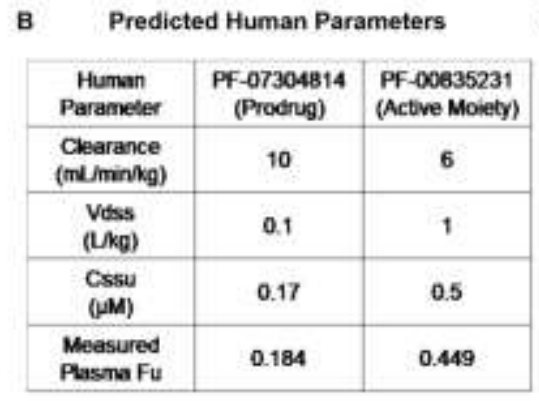

c
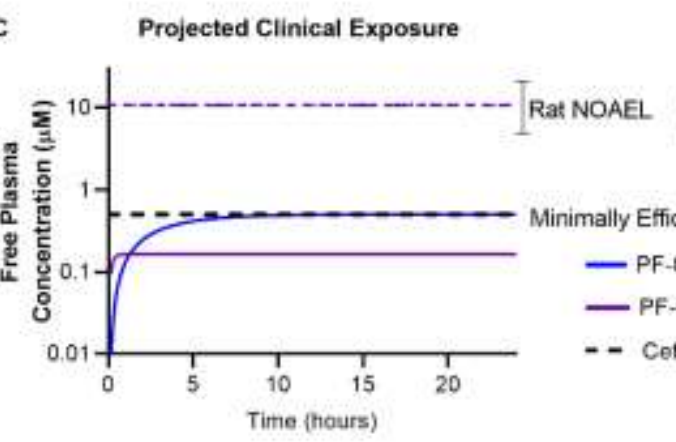

Safety Margins (Ratio of Unbound Conc.) PF- $-07304814: x 65$ AUC, $x 96$ Cmax PF-00835231: $\times 21$ AUC, $\times 25$ Cmax

Fig. 6. PF-07304814 (prodrug) and PF-00835231 in vivo exposure summary. (A) Rat, dog and monkey PK following IV administration of PF-07304814 (1.17mg/kg) or PF-00835231 (2mg/kg rat, $1 \mathrm{mg} / \mathrm{kg}$ dog and monkey) demonstrating high levels of PF-00835231 formed in vivo. $(\mathrm{n}=2)(\mathbf{B})$ Predicted human PK parameters and measured protein binding for PF-07304814 and PF-00835231 used for human dose prediction. (C) Projected human systemic exposure profiles at the minimally efficacious dose of 500mg/day of PF-07304814 delivered as a continuous IV infusion. The predicted unbound steady state concentrations for the prodrug PF07304814 (purple) and the active moiety PF-00835231 (blue) are $0.17 \mu \mathrm{M}$ and $0.5 \mu \mathrm{M}$ respectively. (NOAEL= No Observed Adverse Effect Level; $\mathrm{C}_{\text {eff }}=$ projected minimally efficacious concentration, $\mathrm{Fu}=$ unbound fraction; error bars= range of replicates) 


\section{Supplementary Materials For}

\section{Title: Discovery of a Novel Inhibitor of Coronavirus 3CL Protease for the}

\section{Potential Treatment of COVID-19}

\section{Short Title: Novel 3CL Protease Inhibitor for COVID-19}

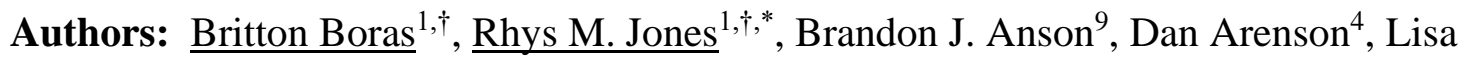
Aschenbrenner ${ }^{4}$, Malina A. Bakowski ${ }^{11}$, Nathan Beutler ${ }^{12}$, Joseph Binder ${ }^{1}$, Emily Chen ${ }^{11}$, Heather Eng ${ }^{4}$, Holly Hammond ${ }^{14}$, Jennifer Hammond ${ }^{6}$, Robert E. Haupt ${ }^{14}$, Robert Hoffman ${ }^{1}$, Eugene P. Kadar ${ }^{4}$, Rob Kania ${ }^{1}$, Emi Kimoto ${ }^{4}$, Melanie G. Kirkpatrick ${ }^{11}$, Lorraine Lanyon ${ }^{4}$, Emma K. Lendy ${ }^{10}$, Jonathan R. Lillis ${ }^{7}$, James Logue ${ }^{14}$, Suman A. Luthra ${ }^{3}$, Chunlong $\mathrm{Ma}^{8}$, Stephen W. Mason ${ }^{2,4}$, Marisa E. McGrath ${ }^{14}$, Stephen Noell ${ }^{4}$, R. Scott Obach ${ }^{4}$, Matthew N. O' Brien $^{5}$, Rebecca O’Connor ${ }^{4}$, Kevin Ogilvie ${ }^{4}$, Dafydd Owen ${ }^{3}$, Martin Pettersson ${ }^{3}$, Matthew R Reese $^{4}$, Thomas F. Rogers ${ }^{12,13}$, Michelle I. Rossulek ${ }^{3}$, Jean G. Sathish ${ }^{2}$, Norimitsu Shirai ${ }^{4}$, Claire Steppan $^{4}$, Martyn Ticehurst ${ }^{7}$, Lawrence W. Updyke ${ }^{3}$, Stuart Weston ${ }^{14}$, Yuao Zhu ${ }^{2}$, Jun Wang ${ }^{8}$, Arnab K. Chatterjee ${ }^{11}$, Andrew D. Mesecar ${ }^{9,10}$, Matthew B. Frieman ${ }^{14}$, Annaliesa S. Anderson ${ }^{2}$, Charlotte Allerton ${ }^{3}$

\section{Affiliations:}

${ }^{1}$ Worldwide Research and Development, Pfizer Inc., La Jolla, CA 92121, ${ }^{2}$ Pearl River, NY 10965, ${ }^{3}$ Cambridge, MA 02139, ${ }^{4}$ Groton, CT 06340, ${ }^{5}$ Lake Forest, IL 60045, ${ }^{6}$ Collegeville, PA 19426, USA, ${ }^{7}$ Sandwich, CT13 9ND, UK

${ }^{8}$ Department of Pharmacology and Toxicology, College of Pharmacy, University of Arizona, Tucson, AZ, 85721

${ }^{9}$ Department of Biological Sciences, ${ }^{10}$ Department of Biochemistry, Purdue University, West Lafayette, IN, 47907 USA.

${ }^{11}$ Calibr, a division of The Scripps Research Institute, La Jolla, CA 92037

${ }^{12}$ Department of Immunology and Microbiology, The Scripps Research Institute, La Jolla, CA 92037

${ }^{13}$ UC San Diego Division of Infectious Diseases and Global Public Health, UC San Diego School of Medicine, La Jolla, CA 92093.

${ }^{14}$ Department of Microbiology and Immunology University of Maryland School of Medicine, Baltimore, MD 21201

$\dagger$ Authors contributed equally.

*Correspondence to: rhys.jones@pfizer.com 


\section{This Supplement includes:}

Materials and Methods

Figures S1-S2

Tables S1-S12

References (35-65)

\section{Materials and Methods}

\section{Thermal Stability Assay}

3CLpro protein $(3 \mu \mathrm{M})$ was incubated with DMSO or $40 \mu \mathrm{M}$ PF-00835231 in reaction buffer (20mM HEPES, pH 6.5, 120mM NaCl, 0.4mM EDTA, 4mM DTT and $20 \%$ glycerol) at $30{ }^{\circ} \mathrm{C}$ for 30 minutes. 1X SYPRO orange dye was added and fluorescence of the well was monitored under a temperature gradient range from $30^{\circ} \mathrm{C}$ to $90^{\circ} \mathrm{C}$ with $0.05{ }^{\circ} \mathrm{C} / \mathrm{s}$ incremental step. The melting temperature $\left(\mathrm{T}_{\mathrm{m}}\right)$ was calculated as the mid-log of the transition phase from the native to the denatured protein using a Boltzmann model in Protein Thermal Shift Software v1.3.

Coronavirus protease panel

Expression and purification of Alpha-, Beta-, and Gamma-coronavirus 3CLpro enzymes. In general, the coding regions for all 14 of the $3 \mathrm{C}$-like proteases described in this study were codonoptimized and synthesized by a commercial source (BioBasic or GeneScript). The coding regions were inserted into a derivative of the pET 11 or pET15 expression vectors that place a hexa-histidine tag at the N-terminus that is followed by a Tobacco-Etch Virus (TEV) protease cleavage site that resides between the coding region of 3CLpro and the hexa-histidine affinity tag. The cleavage site for TEV is also recognized by 3CLpro, and therefore it is autocatalytically cleaved during expression in Escherichia coli, releasing authentic 3CLpro for purification. Each of the 14 coronaviruses were expressed in either E. coli BL21(DE3) or E. coli BL21(DE3) Gold cells and then purified after lysis using a combination of ammonium-sulfate fractionation, hydrophobic-interaction, anion-exchange, cation-exchange and size-exclusion chromatography. With the exception of 3CLpro from h229E, the details of the purifications for the other 13 3CLpros have been described in the literature with some modifications as outlined below.

The expression and purification of 3CLpro from SARS-CoV-2 3CLpro ${ }^{35}$ SARS-CoV-1 ${ }^{36,37}$, MERS ${ }^{38}$, HKU4 ${ }^{39}$, HKU5 ${ }^{40}$, FIPV ${ }^{41}$, PEDV ${ }^{42}$, and MHV ${ }^{43}$ have been previously described. Expression and purification protocols for 3CLpro from NL63, OC43, HKU9 and IBV coronaviruses were performed as described ${ }^{44}$ with the following modifications. NL63 3CLpro was expressed and purified using a modified protocol based on the purification of murine hepatitis virus (MHV) 3CLpro using a DEAE-Cellulose column. OC43 and HKU9 3CLpro were expressed using the autoinduction protocols developed for MERS 3CLpro followed by the same purification method as MHV 3CLpro. Avian coronavirus (IBV) 3CLpro was expressed and purified using a modified protocol based on MERS 3CLpro.

Expression and purification of the human h229E coronavirus 3CLpro was performed using the following method. The sequence for human $\mathrm{h} 229 \mathrm{E}$ was obtained from UniProt (accession AGW80931.1) and was designed to include an N-terminal hexa-histidine tag followed by polyprotein residues 2960 - 3267. This gene sequence was codon-optimized for expression in $E$. coli and subcloned into a pET11a vector using the synthetic DNA services of GenScript Biotech (Piscataway, NJ). The pET11a plasmid containing the 229E 3CLpro gene was electroporated into E. coli BL21-GOLD (DE3) cells. A single colony of the transformed cells was used to 
inoculate $100 \mathrm{~mL}$ of $2 \mathrm{xYT}$ media $(10 \mathrm{~g}$ yeast extract, $16 \mathrm{~g}$ tryptone, $5 \mathrm{~g} \mathrm{NaCl}$ per $1 \mathrm{~L}$ of water, $100 \mu \mathrm{g} / \mathrm{mL}$ carbenicillin, $\mathrm{pH}$ adjusted to 7.50 using $10 \mathrm{M} \mathrm{NaOH}$ ). The preculture was incubated at $37^{\circ} \mathrm{C}$ until the culture reached an $\mathrm{OD}_{600}$ of $0.6 .15 \mathrm{~mL}$ of the preculture was added to $1 \mathrm{~L}$ of $2 \mathrm{xYT}$ expression media and incubated at $37^{\circ} \mathrm{C}$ until an $\mathrm{OD}_{600}$ of 0.6 was reached. The cultures were then placed on ice for 15 minutes before addition of isopropyl B-D-1-thiogalactopyranoside (IPTG) to a final concentration of $0.6 \mathrm{mM}$ and further incubated at $25^{\circ} \mathrm{C}$. After 16 hours, the cells were harvested via centrifugation at $10,940 \mathrm{x} g$ for 10 minutes to yield an $8.3 \mathrm{~g}$ cell pellet per $\mathrm{L}$. The cell pellet was resuspended in 5mL Lysis Buffer (25mM HEPES, 0.05mM EDTA, 5mM $\beta$ mercaptoethanol ( $\beta$-ME), $1 \mathrm{mg} / \mathrm{mL}$ lysozyme) per $1 \mathrm{~g}$ of pelleted cells using a manual homogenizer. The homogenized cell suspension was sonicated for a total of 12 minutes at an amplitude of $60 \%$ for periods of 10 seconds with 20 second delays using a Branson digital sonifier. Solid ammonium sulfate was slowly added to the resulting lysate to a final concentration of $1 \mathrm{M}$ and stirred at $25^{\circ} \mathrm{C}$ for 10 minutes. The lysate was then clarified via centrifugation at $20,442 \times \mathrm{g}$ for 45 minutes at $4^{\circ} \mathrm{C}$.

The resulting supernatant was checked for activity prior to being applied to a $75 \mathrm{~mL}$ Phenyl Sepharose (GE Healthcare) resin equilibrated in Buffer B (1 M ammonium sulfate, 50mM HEPES, $\mathrm{pH} 7.50,0.05 \mathrm{mM}$ EDTA, $5 \mathrm{mM} \beta \mathrm{ME})$. The protein was eluted off the column using a linear gradient to $100 \%$ Buffer A (25mM HEPES, 0.05mM EDTA, 5mM $\beta$-ME) over 5 column volumes, followed by a water wash. $2 \mathrm{~mL}$ fractions that eluted in water containing 229E 3CLpro were mixed with $8 \mathrm{~mL}$ of $5 \mathrm{X}$ Buffer A. Fractions were assessed for purity via SDS-PAGE and enzymatic activity based on specific activity prior to pooling. The resulting protein pool was filtered using a $0.45 \mu \mathrm{m}$ surfactant-free cellulose acetate membrane prior to injection onto an $8 \mathrm{~mL}$ MonoQ column equilibrated in Buffer A. The protein was eluted using a linear gradient to $100 \%$ Buffer C (1 M NaCl, 50mM HEPES, pH 7.50, 0.05mM EDTA, 5mM $\beta \mathrm{ME})$ over 15 column volumes. Fractions were pooled based on purity and specific activity and concentrated to 2.5mL using a 10,000 molecular weight cutoff (MWCO) spin concentrator (MilliporeSigma). The sample was then injected onto an SRT SEC-300 column (Sepax Technologies) that had been equilibrated in Buffer D (50mM HEPES, pH 7.50, 10\% glycerol, 2.5mM dithiothreitol (DTT)). The resulting protein was pooled based on the criteria above, aliquoted and flash-frozen in liquid nitrogen, and stored at $-80^{\circ} \mathrm{C}$.

Inhibitor characterization of 3CLpro enzymes.

Inhibition of all 3CLpro enzymes was measured using a continuous, FRET assay. The increase in fluorescence due to the cleavage of a custom-synthesized substrate, UIVT3 (HiLyte

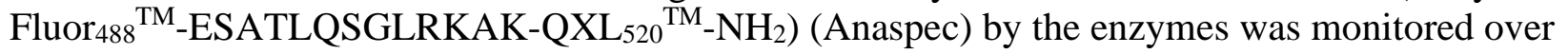
time. All $\mathrm{K}_{\mathrm{i}}$ determinations were performed in Costar 3694 EIA/RIA 96-well, half-area, flat bottom, black polystyrene plates (Corning) using an assay buffer that contained 50mM HEPES (pH 7.5), $0.1 \mathrm{mg} / \mathrm{mL}$ bovine serum albumin (BSA), $0.01 \%$ Triton $\mathrm{X}-100$ and $2 \mathrm{mM}$ DTT. The final assay volume was $100 \mu \mathrm{L}$ and all assays were performed in triplicate. $1 \mu \mathrm{L}$ of $100 \mathrm{X}$ inhibitor stocks, prepared in 100\% DMSO, were added to assay buffer and incubated for 5 minutes at $25^{\circ} \mathrm{C}$. Then, 3CLpro enzyme was added to the mixture and incubated for 10 minutes at $25^{\circ} \mathrm{C}$. The final concentrations of each coronaviral 3CLpro enzyme are listed below and they are different depending on the coronavirus. All reactions were initiated with the addition of UIVT3 substrate to a final concentration of $2 \mu \mathrm{M}$.

The fluorescence of the substrate (excitation $485 \mathrm{~nm} /$ emission $528 \mathrm{~nm}$ ) was measured using either a CLARIOstar Plate Reader (BMG Labtech) or Synergy H1 hybrid multi-mode plate reader (Biotek). The initial rates at each inhibitor concentration were obtained by dividing the 
Relative Fluorescence Units (RFU) produced during the initial rate period of the enzyme by time in minutes, yielding RFU $\min ^{-1}$. Initial velocities were calculated by dividing the observed velocity in the absence of inhibitor $\left(V_{o}\right)$ by the initial velocity at different inhibitor concentrations $\left(\mathrm{V}_{\mathrm{i}}\right)$. $\mathrm{K}_{\mathrm{i}}$ values, with the exception of MERS 3CLpro, were obtained by fitting the data to the Morrison equation (Equation 1) for tight-binding inhibitors ${ }^{45}$.

$$
\frac{V_{i}}{V_{o}}=\frac{[E]_{o}+[I]_{o}-K_{i}\left(1+\frac{[S]}{K_{m}}\right)}{2[E]_{o}}+\frac{\sqrt{\left([I]_{o}+K_{i}\left(1+\frac{[S]}{K_{m}}\right)-[E]_{o}\right)^{2}+4[E]_{o} K_{i}\left(1+\frac{[S]}{K_{m}}\right)}}{2[E]_{o}}(3)
$$

For these fits, the $\mathrm{V}_{\max }$ was initially set to a value less than 1.2, the UIVT3 substrate concentration was fixed at $2 \mu \mathrm{M}$, and the $\mathrm{K}_{\mathrm{m}}$ value was fixed at a value of $250 \mu \mathrm{M}$. The $\mathrm{K}_{\mathrm{m}}$ value for the UIVT3 substrate is estimated to be higher as even after correcting for inner-filter effects via dilution experiments, the 3CLpro enzymes were not saturated with substrates as the response of the enzyme to increasing UIVT3 substrate concentrations was linear over the range of 1 to $250 \mu \mathrm{M}$.

The total enzyme concentrations were experimentally determined by measuring their absorbance at $280 \mathrm{~nm}$ and using their respective molar extinction coefficients $\varepsilon_{280}$ calculated based on their primary amino acid sequences. The values for enzyme concentration $[\mathrm{E}]_{\mathrm{o}}$ in Equation 3 were not fixed during the curve-fitting process. The resulting enzyme concentrations from the Morrison equation fit are represented in the parentheses following the experimentally determined total enzyme concentrations as follows: 200nM SARS-2 (188 $\pm 10 \mathrm{nM}), 200 \mathrm{nM}$ SARS (153 \pm 2nM), 1000nM MERS, 250nM NL63 (170 \pm 4nM), 125nM HKU1 (59 \pm 2nM), 100nM HKU4 (60 $\pm 1 \mathrm{nM}), 125 \mathrm{nM}$ HKU5 (74 $\pm 1 \mathrm{nM}), 400 \mathrm{nM}$ HKU9 (265 \pm 5nM), 200nM 229E $(116 \pm 3 n M), 100 n M$ OC43 $(51 \pm 1 n M), 100 n M$ PEDV $(40 \pm 1 n M), 100 n M$ MHV $(75 \pm$ 4nM), 25nM FIPV (36 $\pm 1 \mathrm{nM}), 50 \mathrm{nM}$ IBV (31 $\pm 1 \mathrm{nM})$. MERS 3CLpro data were calculated using Equation (4) and fit to the substrate inhibition equation. $\% \mathrm{~V}_{\max }$ is the maximum percent activity observed. All fits were performed using GraphPad Prism 8.3.

$$
\% \text { Rate }=\frac{\% V_{\text {max }} *[\text { Inhibitor }]}{K_{a, a p p}+[\text { Inhibitor }] *\left(1+\frac{[\text { Inhibitor }]}{K_{\text {i app }}}\right)}(4)
$$

\section{Mammalian Protease panel}

The respective protease in assay buffer $(50 \mathrm{mM}$ Tris with $100 \mathrm{mM}$ sodium chloride and Brij 35 at $\mathrm{pH}=8$ except for cathepsin $\mathrm{D} \mathrm{pH}=3.5$ and $\mathrm{HIV} \mathrm{pH}=5.5$ ) was added to assay ready compound plates. The enzymatic reaction was initiated with the addition of indicated substrate in assay buffer. Final concentrations of respective protease and substrate are shown in Table S12. Initial rates were measured by following the fluorescence of the cleaved substrate (Ex/Em 355/460nM) using a Spectramax (Molecular Devices) fluorescence plate reader in the kinetic format.

Percent inhibition values were calculated based on control wells containing no compound (0\% inhibition) and wells containing a control compound (100\% inhibition). $\mathrm{IC}_{50}$ values were generated based on a four-parameter logistic fit model using ActivityBase software (IDBS). Percent activity values were calculated based on control wells containing no compound (100\% activity) and wells containing a control compound ( $0 \%$ activity).

Antiviral activity 
The ability of compounds to inhibit viral induced cytopathic effect (CPE) against human coronaviruses (SARS-CoV-1, SARS-CoV-2, hCoV-229E) was assessed by monitoring cell viability using two different assay endpoints in VeroE6 or MRC-5 cells. VeroE6 cells that are enriched for hACE2 expression were batched inoculated with SARS-CoV-2 (USA_WA1/2020) at a multiplicity of infection (MOI) of 0.002 in a BSL-3 lab (Southern Research Institute). Virus inoculated cells are then added to assay ready compound plates at a density of 4,000 cells/well in DMEM containing $2 \%$ heat inactivated eFBS. Following a 3-day incubation at $37^{\circ} \mathrm{C}$ with $5 \%$ $\mathrm{CO}_{2}$, a time at which virus-induced cytopathic effect is $95 \%$ in the untreated, infected control conditions. Cell viability was evaluated using Cell Titer-Glo (Promega), according to the manufacturer's protocol, which quantitates ATP levels. Cytotoxicity of the compounds was assessed in parallel in assay ready compound plates with non-infected cells.

VeroE6-EGFP cells were seeded at a density of 2,000 cells/well in DMEM containing 2\% FCS and $0.08 \%$ sodium bicarbonate were seeded into 384-well cell culture microplates containing the serially diluted test compounds. Immediately following cell seeding, virus (SARS-CoV-2 (Belgium strain) or SARS-CoV-1 (CDC 200300592)) was added at a MOI of 0.015 equaling $~ 30$ PFU in a Caps-It isolator system (Rega Institute). The plates were then automatically transferred to an integrated incubator and incubated for 5 days at $37^{\circ} \mathrm{C}$ with $5 \%$ $\mathrm{CO}_{2}$, a time at which virus-induced cytopathic effect is $100 \%$ in the untreated, infected control conditions (virus controls). Uninfected assay ready compound plates were treated the same way and were used to measure compound cytotoxicity. To monitor the EGFP fluorescence, the plates were transferred to a high-content imager for fluorescence microscopy. A 5x objective was used to capture one field per well (approximately $70 \%$ of the well). The images were captured with one channel on auto-focus, a fixed exposure time of 0.023 seconds and with a fixed objective offset ( $\mathrm{z}$ offset). For the image analysis, the SpotDetector bio-application from the Cellomics software was used, which requires two (2) channels, one (1) for object identification (first channel) and one (1) for signal/spots identification (second channel). The Valid Object Count reported value was the total count of the number of nuclei.

MRC-5 cells, seeded at a density of 20,000 cells/well were incubated overnight in MEM containing 5\% FBS at 37oC and 5\% CO2. (Wuxi AppTech). The following day test compounds, HCoV-229E virus (ATCC VR-740) (200 TCID50) was added at concentrations which correspond to a multiplicity of infection (MOI) of 0.007, were added to the MRC-5 cells. Cells were incubated for 3 days at $35^{\circ} \mathrm{C}$ with $5 \% \mathrm{CO} 2$ and cell viability was evaluated using the CellTiter Glo (Promega) post the 3-day incubation, according to the manufacturer's protocol. Cytotoxicity of test compounds was assessed in parallel with cells plated 1 day prior to addition of compound, but incubated for 5 days with compound only, and then treated with CellTiter Glo (Promega).

Test compound(s) were tested either alone or in the presence of the $\mathrm{P}$ glycoprotein (P-gp) inhibitor, CP-100356 at indicated concentrations of either 0.5 or $2 \mu \mathrm{M}$. The inclusion of CP 100356 was to assess if the test compound(s) were being effluxed out of cells due to expression of P-glycoprotein.

Percent effect at each concentration of test compound was calculated based on the values for the no virus control wells and virus containing control wells on each assay plate. The concentration required for a $50 \%$ response $\left(\mathrm{EC}_{50}\right)$ value was determined from these data using a 4-parameter logistic model. $\mathrm{EC}_{50}$ curves were fit to a Hill slope of 3 when $>3$ and the top dose achieved $\geq 50 \%$ effect. If cytotoxicity was detected at greater than $30 \%$ effect, the corresponding concentration data was eliminated from the $\mathrm{EC}_{50}$ determination. For cytotoxicity plates, a percent 
effect at each concentration of test compound was calculated based on the values for the cell only control wells and hyamine or no cell containing control wells on each assay plate. The $\mathrm{CC}_{50}$ value was calculated using a 4-parameter logistic model. A therapeutic index (TI) was then calculated by dividing the $\mathrm{CC}_{50}$ value by the $\mathrm{EC}_{50}$ value.

Drug combination studies were performed using HeLa-ACE2 cells in a high content imaging assay. HeLa-ACE2 cells were seeded at a density of 1.0×103 cells per well in DMEM containing $2 \%$ FBS into the 384-well $\mu$ clear-bottom assay ready compound plates. Plated cells were transferred to the BSL-3 facility where $13 \mu \mathrm{L}$ of SARS-CoV-2 (strain USA-WA1/2020, propagated in Vero E6 cells) diluted in DMEM with 2\% FBS was added per well at a concentration to achieve $\sim 30-50 \%$ infected cells. Plates were incubated for 24 hours at $34^{\circ} \mathrm{C}$ with $5 \% \mathrm{CO} 2$, and then fixed with $25 \mu \mathrm{L}$ of $8 \%$ paraformaldehyde for 1 hour at $34^{\circ} \mathrm{C}$ with $5 \%$ CO2. Plated cells were transferred to the BSL-3 facility where SARS-CoV-2 (strain USAWA1/2020) was added per well at a concentration to achieve $\sim 30-50 \%$ infected cells. Plates were incubated for 24 hours at $34^{\circ} \mathrm{C}$ with $5 \% \mathrm{CO} 2$, and then fixed with $25 \mu \mathrm{L}$ of $8 \%$ paraformaldehyde for 1 hour at $34^{\circ} \mathrm{C}$ with $5 \% \mathrm{CO} 2$. Plates were washed with $1 \mathrm{X}$ phosphate buffered saline (PBS) containing $0.05 \%$ Tween 20 after fixation, primary and secondary antibody staining. Human polyclonal sera, from two different recovered patients, was diluted 1:500 in Perm/Wash buffer, added to the plate and incubated at room temperature for 2 hours for primary staining. Six $\mu \mathrm{g} / \mathrm{mL}$ of goat anti-human $\mathrm{H}+\mathrm{L}$ conjugated Alexa 488 together with $8 \mu \mathrm{M}$ of antifade-4,6-diamidino-2-phenylindole dihydrochloride (DAPI) in SuperBlock T20 (PBS) blocking buffer was added and incubated at room temperature for 1 hour in the dark for secondary staining. Plates were imaged using the ImageXpress Micro Confocal High-Content Imaging System (Molecular Devices) with a 10× objective, with 4 fields imaged per well. Images were analyzed using theMulti-Wavelength Cell Scoring Application Module (MetaXpress). The total number of cells were determined with DAPI staining to identify the host-cell nuclei and the number of SARS-CoV-2 infected cells were determined by the SARSCoV-2 immunofluorescence.

Data were analyzed using Genedata Screener, Version 17.0.1-Standard. Primary invitro screen and the host cell toxicity screen data [\% Positive W2 (MultiWaveScoring)] were uploaded to Genedata Screener. For EC S0 $_{50}$ determinations, data were normalized to negative inhibition controls (DMSO) minus positive viral inhibitor controls $(2.5 \mu \mathrm{M}$ remdesivir) and for host cell cytotoxicity in the viral infected cells (concentration required for 50\% cytotoxicity; $\mathrm{CC}_{50}$ ), data were normalized to negative cytotoxic controls (DMSO) minus positive cytotoxic controls (10 $\mu \mathrm{M}$ puromycin). The "\% Positive W2 (MultiWaveScoring)" and "Total Cells (MultiWaveScoring)" values were used for analysis of antiviral effect and host cell toxicity, respectively. Compounds were tested in technical triplicates on different assay plates and dose curves were fitted with the four parameter Hill Equation. Replicate data were analyzed using median condensing. GeneData Screener was used to assess drug combination effects, at $90 \%$ effect, using the Loewe, Bliss, and HSA models or SynergyFinder using the ZIP model ${ }^{46}$.

In general, a synergy score of $>1$ and a combination index of $<1$ indicate that the combination treatment has a synergistic effect ${ }^{24}$. To assess whether synergy could be achieved at high inhibition levels, the isobologram level was set at 0.9 to capture meaningful synergy with a $90 \%$ viral reduction (equivalent to a $1 \log _{10}$ reduction).

\section{$\underline{\text { In vivo efficacy studies in MA-SARS-CoV-1 mouse model }}$}

Animal treatment and subsequent observations of animal weight, and virus titration were conducted in the BSL-3 laboratory at University of Maryland College Park under IACUC 
approved protocols. Mice housed in the BSL-3 were anesthetized with ketamine/xylazine mixture and intranasally inoculated with $1 \times 10^{5}$ pfu of MA15-SARS-CoV-1 in $50 \mu \mathrm{L}$ of PBS total volume. In all experiments the vehicle for PF-00835231 was $0.05 \%$ (v/v) polysorbate- 80 , $0.1 \%(\mathrm{w} / \mathrm{v})$ sodium carboxymethylcellulose, dosed at $10 \mathrm{~mL} / \mathrm{kg}$ S.C. BID. While on study, mice were weighed daily and observed for clinical signs of disease. At day 4 post-infection, 5 mice per group were euthanized by isoflurane inhalation and lung lobes were either fixed in $4 \%$ paraformaldehyde (PFA) at $4^{\circ} \mathrm{C}$ or placed in $1 \mathrm{ml} \mathrm{PBS}$ with sterile glass beads at $-80^{\circ} \mathrm{C}$.

For histopathology, lungs in 4\% PFA were removed from the BSL3 at least 24 hours after they were added to PFA and embedded in paraffin for sectioning and H\&E staining at the University of Maryland at Baltimore Histology Core. Slides were read by Norimitsu Shirai in the Pfizer Cambridge, DSRD Global Pathology group.

MA15-SARS-CoV-1 lung titers were quantified by homogenizing mouse lungs in $1 \mathrm{ml}$ phosphate buffered saline (PBS) using $1.0 \mathrm{~mm}$ glass beads and a Beadruptor. VeroE6 cells are plated in 6 well plates with $1 \times 10^{5}$ cells per well. MA15-SARS-CoV-1 virus titer in plaque forming units was determined by plaque assay: $25 \mu \mathrm{L}$ of the lung homogenate was added to $225 \mu \mathrm{L}$ of PBS and diluted 10-fold across a 6-point dilution curve with $200 \mu \mathrm{L}$ of diluent added to each well. After 1 hour, a $3 \mathrm{~mL}$ agar overlay containing MEM was added to each well. Plates were incubated for 3 days at $37^{\circ} \mathrm{C}\left(5 \% \mathrm{CO}_{2}\right)$ before plaques were counted.

$\underline{\text { LogD, solubility and } \mathrm{pKa} \text { measurements }}$

The LogD of PF-00835231 was measured at $\mathrm{pH} 7.4$ using the previously described shake-flask method $^{47}$. The LogD of PF-07304814 was predicted using ACDlabs (v2019.1.1). Solubility was measured at room temperature by slurrying the solid drug substance in deionized water and $\mathrm{pH}$ buffers for 48 hours, filtering the slurry through $10.2 \mu \mathrm{m}$ and analyzing the filtrate using LC-UV spectrometry. The pKa was measured by calculating inflection points in the chemical shift of $1 \mathrm{H}$ using solution NMR as a function of $\mathrm{pH}$ using ${ }^{1} \mathrm{H} /{ }^{31} \mathrm{P}$ NMR data collected on a $600 \mathrm{MHz}$ spectrometer at $298 \mathrm{~K}$ as described in a previously published method ${ }^{48}$.

Metabolism of PF-00835231 in human liver microsomes: intrinsic clearance and effects of CYP3A inhibitors

In vitro lability in pooled human liver microsomes was determined as follows. PF-00835231 (1 $\mu \mathrm{M})$ was incubated with human liver microsomes $(2.0 \mathrm{mg} / \mathrm{mL}$; custom mixed sex pool from 50 donors, Xenotech, Lenexa, KS) in a volume of $1 \mathrm{~mL}$ potassium phosphate $(100 \mathrm{mM} ; \mathrm{pH} 7.5)$ containingmgCl $2(3.3 \mathrm{mM})$ and $\mathrm{NADPH}(1.3 \mathrm{mM})$ at $37^{\circ} \mathrm{C}$ in a shaking water bath. At $0,5,10$, $20,30,45$, and 60 minutes, aliquots $(0.1 \mathrm{~mL})$ were removed and added to $0.5 \mathrm{~mL}$ acetonitrile containing saquinavir $(0.2 \mu \mathrm{M})$ as an internal standard to terminate the reaction. Precipitated protein was removed by spinning in a centrifuge (1700 x g; 5 minutes) and the supernatant was removed in a vacuum centrifuge. The residues were reconstituted in $0.05 \mathrm{~mL}$ of $1 \%$ formic acid in $20 \%$ acetonitrile for analysis by high-performance liquid chromatography-tandem mass spectrometry (HPLC-MS). Intrinsic clearance by substrate depletion was calculated as previously described ${ }^{49}$. Enzyme kinetics were determined by product formation. PF-00835231 $(0.25-500 \mu \mathrm{M})$ was incubated in pooled human liver microsomes $(0.5 \mathrm{mg} / \mathrm{mL})$ in $0.1 \mathrm{~mL}$ potassium phosphate $(100 \mathrm{mM} ; \mathrm{pH} 7.5)$ containingmgCl 2 (3.3mM) and $\mathrm{NADPH}(1.3 \mathrm{mM})$. Incubations were carried out at $37^{\circ} \mathrm{C}$ by shaking in a humidified incubator $(85 \%$ relative humidity) for 20 minutes and terminated with the addition of $0.5 \mathrm{~mL}$ acetonitrile containing saquinavir $(0.1 \mu \mathrm{M})$ as an internal standard. Terminated incubation mixtures were processed as 
described above and analyzed by HPLC-MS. Quantitation of the four main metabolites, which had been generated by biosynthesis and qNMR using a previously described method ${ }^{50}$, was done against standard curves ranging from 1-10000nM. Experiments to evaluate the role of CYP3A were conducted in a similar fashion, using a substrate concentration of $4.0 \mu \mathrm{M}$, and concentrations of ketoconazole ranging from 1-10000nM. To evaluate the potential contribution of CYP3A5, the comparative effects of ketoconazole vs cyp3cide (both at $1.0 \mu \mathrm{M}$ ) on the formation of four metabolites of PF-00835231 (at $4 \mu \mathrm{M}$ ) were measured in a custom pool of liver microsomes from four CYP3A5 EM donors, using the same incubation conditions described above. All measurements were made in a minimum of triplicate incubations.

Metabolic stability of PF-07304814 in human liver S9

Human liver S9 (HLS9) was purchased from BioIVT (Westbury, NY) as a custom pool of 6 donors prepared in the absence of EDTA and PMSF. The experimental conditions used for enzyme kinetics studies in liver S9 were chosen to yield linear reaction velocities as determined from preliminary range finding experiments. Stock solutions of PF-07304814 were prepared in 10/90 acetonitrile/water at 10-times the intended incubation concentration. Incubations were conducted in $100 \mathrm{mM}$ Tris buffer $(\mathrm{pH} 7.5)$ containing $5 \mathrm{mMmgCl}_{2}$ and $0.03 \mathrm{mg} / \mathrm{mL} \mathrm{S} 9$ protein at $37^{\circ} \mathrm{C}$ open to air. The concentrations of PF-07304814 ranged from 0.3 to $300 \mu \mathrm{M}$ and the final incubation volume was $20 \mu \mathrm{L}$. Reactions were initiated by the addition of substrate into enzyme matrix and were terminated after 20 minutes with $100 \mu \mathrm{L}$ of acetonitrile containing $1 \%$ formic acid and IS (50 ng/mL indomethacin). To minimize saturation of MS detection, a 10-fold dilution of samples containing the highest substrate concentrations was conducted prior to precipitation. Samples were vortexed, centrifuged, and $75 \mu \mathrm{L}$ of supernatant was combined with $200 \mu \mathrm{L}$ of $1 \%$ formic acid in water for injection onto LC-MS system for analysis. Incubations for enzyme kinetic determination in liver S9 were conducted in triplicate. Enzyme kinetics were analyzed as described above for HLM using the Michaelis-Menten model with a second unsaturable component. The apparent intrinsic clearance for PF-07304814 in liver S9 across species was calculated using equation 5.

$$
C L_{\text {int, app }}=\frac{V \max }{K m}(5)
$$

\section{$\underline{\text { Reversible inhibition of CYP enzymes in human liver microsomes }}$}

CYP selective marker substrates were purchased from various commercial sources: furafylline, ticlopidine, paroxetine, phenacetin, acetaminophen, diclofenac, dextromethorphan and dextrophan were obtained from Sigma Aldrich (St. Louis, MO); S-mephenytoin from Toronto Research Chemicals (North York, ON); verapamil from Sequoia Research Products (Pangbourne, United Kingdom); amodiaquine from Fluka (Bucks, Switzerland); 4'-OH-Smephenytoin and [2H3]4'-OH-S-mephenytoin from Syncom (Groningen, Netherlands); Ndesethylamodiaquine, [2H5] N-desethylamodiaquine, tienilic acid, and [2H3]-dextrophan from Cerilliant (Round Rock, Texas); gemfibrozil glucuronide, 4' -OH diclofenac, and [13C6]4' -OH diclofenac were from Pfizer Inc (Groton, CT). Reversible inhibition was measured in a coincubation of PF-00835231 with marker substrate (at approximately KM concentration) with HLM $(0.01-0.1 \mathrm{mg} / \mathrm{ml})$ and NADPH $(1.3 \mathrm{mM})$ in $100 \mathrm{mM}$ potassium phosphate buffer containing $3.3 \mathrm{mMmgCl} 2(\mathrm{pH} 7.4)$ in a final incubation volume of $0.2 \mathrm{~mL}$ in a $37^{\circ} \mathrm{C}$ dry heat bath open to air. After a 4-20 min incubation time, reactions were quenched with 2-volumes of acetonitrile 
containing internal standard $(2 \mathrm{H}$ or $13 \mathrm{C}$ labeled analyte). To qualitatively determine the potential for TDI, all incubation components except marker substrate were preincubated for 30 min, followed by addition of marker substrate for the specified reaction time. PF-00835231 was tested at concentrations 0.1 to $200 \mu \mathrm{M}$ in triplicate. Terminated incubation mixtures were centrifuged at $2000 \mathrm{~g}$ for $5 \mathrm{~min}$, resulting supernatants were evaporated to dryness under nitrogen followed by reconstitution in mobile phase (20\% acetonitrile in $1 \%$ aqueous formic acid). Samples were analyzed by LC-MS. Analytes were quantified versus a standard curve using GraphPad Prism v8 (San Diego, CA) or Sciex Analyst software. IC 50 calculations were conducted in GraphPad using equation 6.

$$
Y=\text { Bottom }+\left(\frac{\text { Top-Bottom }}{1+\frac{X^{\text {Hillslope }}}{I C_{50}^{\text {Hilllope }}}}\right)(6)
$$

TDI signal was defined having either at least a 1.5 -fold decrease in $\mathrm{IC}_{50}$ value after a 30 minute preincubation or there was at least a $20 \%$ increase in inhibition observed after a 30 minute preincubation for any concentration examined. A TDI signal resulted in determination of $\mathrm{K}_{\mathrm{I}}$ and $\mathrm{k}_{\text {inact. }}$ For inhibition studies conducted in cassette format, incubations were conducted as described above with the following modifications: HLM concentration was $0.03 \mathrm{mg} / \mathrm{mL}$, probe substrates bupropion and testosterone were excluded, and the activity reaction time was 6 minutes.

\section{Time-dependent inhibition of CYP enzymes in human liver microsomes}

$\mathrm{K}_{\mathrm{I}}$ and $\mathrm{k}_{\text {inact }}$ studies were measured in a co-incubation of PF-00835231 with HLM (0.2$0.3 \mathrm{mg} / \mathrm{mL})$ and NADPH $(1.3 \mathrm{mM})$ in $100 \mathrm{mM}$ potassium phosphate buffer containing $3.3 \mathrm{mMmgCl}_{2}(\mathrm{pH} 7.4)$ in a final incubation volume of $0.2 \mathrm{~mL}$ in a $37^{\circ} \mathrm{C}$ dry heat bath open to air. After a 1-50-minute preincubation time, an aliquot of incubate was diluted 20-fold into prewarmed buffer containing marker substrate (5-10 times above $\mathrm{K}_{\mathrm{M}}$ concentration), followed by an activity incubation: $20 \mu \mathrm{M}$ midazolam (midazolam 1'-hydroxylation) 4 minutes with $0.2 \mathrm{mg} / \mathrm{mL}$ HLM; CYP3A, $386 \mu \mathrm{M}$ testosterone (testosterone $6 \beta$-hydroxylation) 11 minutes with $0.3 \mathrm{mg} / \mathrm{mL}$ HLM. Reactions were quenched with 2-volumes of acetonitrile containing internal standard $\left({ }^{2} \mathrm{H}\right.$ or ${ }^{13} \mathrm{C}$ labeled marker product) and treated as described above for $\mathrm{IC}_{50}$ samples. Estimation of the TDI inactivation parameters was performed using Excel and GraphPad software. Percent activity remaining was obtained by normalizing the concentration of marker substrate formed in each sample to the mean solvent control at the first preincubation time point. The natural $\log (\ln )$ of the percentage remaining activity was plotted against the preincubation time. The slope (- $\mathrm{k}_{\mathrm{obs}}$, observed rate) of each line was then calculated for the linear portion of the curve and the non-linear outliers, as determined by GraphPad automatic outlier elimination, were excluded. A statistical test was applied at each inhibitor concentration to evaluate if $\mathrm{k}_{\mathrm{obs}}$ was significantly different from the solvent control (equation 7$)^{51}$.

$$
z=\frac{\left|k_{\mathrm{obs}[1]}-k_{\mathrm{obs}[0 \mu \mathrm{M}]}\right|}{\sqrt{S E_{\widehat{k}_{\mathrm{obs}[1]}^{2}}^{2}+S E_{\widehat{k}_{\mathrm{obs}[0 \mu \mathrm{M}]}^{2}}^{2}}}(7)
$$

In this equation, $\mathrm{k}_{\mathrm{obs}[\mathrm{I}]}, \mathrm{k}_{\mathrm{obs}[0 \mu \mathrm{M}]}$, and S.E. represent the inactivation rate at each inhibitor concentration, inactivation rate with solvent control, and standard error, respectively. When $\mathrm{p}<0.05$, there was statistically significant or measurable TDI. $\mathrm{K}_{\mathrm{I}}$ and $k_{\text {inact }}$ were calculated from 
the nonlinear regression of a 3-parameter Michaelis-Menten equation (equation 8) using GraphPad.

$$
\mathrm{k}_{\mathrm{obs}}=\mathrm{k}_{\mathrm{obs}[0 \mu \mathrm{M}]}+\frac{k_{\text {inact }} \times[I]}{\mathrm{k}_{\mathrm{I}}+[\mathrm{I}]}(8)
$$

$\underline{\text { In vitro transporter inhibition studies using transporter-transfected cells }}$

HEK293 cells, wild-type and stably transfected with OATP1B1, OATP1B3, OCT1, OCT2, MATE1 and MATE2K, were seeded at a density of $0.5-0.7 \times 10^{5}$ cells/well on BioCoat ${ }^{\mathrm{TM}}$ PolyD-Lysine 96-well plates (Corning) and grown in Dulbecco's modified Eagle's medium containing 10\% FBS, 1\% sodium pyruvate, 1\% GlutaMAX ${ }^{\mathrm{TM}}$, 1\% Gentamicin and 1\% nonessential amino acids for $48-72$ hours at $37^{\circ} \mathrm{C}, 90 \%$ relative humidity, and $5 \% \mathrm{CO}_{2}$. For the inhibition studies, HEK293 cells were washed three times with warm transport buffer (Hanks' balanced salt solution with 20mM 4-(2-Hydroxyethyl) piperazine-1-ethanesulfonic acid, $\mathrm{pH} 7.4$ ) followed by incubation with test compounds containing probe substrates: 10 or $20 \mu \mathrm{M}\left[{ }^{14} \mathrm{C}\right]-$ metformin (OCT1, OCT2, MATE1, MATE2K), $0.5 \mu \mathrm{M}\left[{ }^{3} \mathrm{H}\right]$ para-aminohippuric acid (OAT1), $0.1 \mu \mathrm{M}\left[{ }^{3} \mathrm{H}\right]$ estrone-3-sulfate (OAT3) or $0.5 \mu \mathrm{M}$ rosuvastatin (OATP1B1/1B3). Uptake was terminated by washing cells at least three times with ice-cold transport buffer and then lysing with $0.2 \mathrm{~mL}$ of scintillation fluid or $0.225 \mathrm{~mL}$ of methanol containing internal standard. For radiolabeled compounds, radioactivity in each sample was quantified by measurement on MicroBeta (Perkin Elmer). For rosuvastatin, cell extracts were dried down under nitrogen and reconstituted in 50:50 (v:v) methanol:water prior to injection onto a LC-MS/MS system. The total cellular protein content was determined by using a BCA Protein Assay Kit (Pierce Biotechnology) following the manufacturer's protocol. Uptake ratio was then derived as a ratio of accumulation in transfected cells to accumulation in wild-type cells. The half-maximal inhibitory concentration ( $\mathrm{IC}_{50}$ ) for each transporter was calculated in GraphPad Prism.

$(\mathrm{HEK}=$ Human embryonic kidney; OATP $=$ Organic anion transporting polypeptide; OCT $=$ Organic cation transporter; MATE $=$ Multi drug and toxin extrusion protein)

$\underline{\text { In vitro transporter inhibition studies using membrane vesicles }}$

Vesicle assay buffer (10mM Tris base, $250 \mathrm{mM}$ sucrose, $10 \mathrm{mM}$ magnesium chloride) and stop buffer (assay buffer plus 100mM sodium chloride) were prepared at $\mathrm{pH}$ 7.4. For inhibition assays, HEK293, human BCRP and human MDR1 (P-gp) vesicles were diluted to $50 \mu \mathrm{g} / \mathrm{well}$ in assay buffer and were treated with $5 \mathrm{mM}$ ATP, $0.2 \mu \mathrm{M}$ rosuvastatin (BCRP), or $0.2 \mu \mathrm{M}$ N-methyl quinidine (MDR1) and varied concentrations of test compounds. BCRP and MDR1 assays were incubated for 1 and 1.5 minutes, respectively, at $22^{\circ} \mathrm{C}$ while shaking. Reactions were stopped by adding $0.2 \mathrm{~mL}$ of ice-cold stop buffer. The entire reaction was quickly removed from the assay plate and filtered on Multiscreen filter plate (Millipore) and then washed four times with ice-cold stop buffer. Intravesicle samples were extracted by treating the vesicles with $0.15 \mathrm{~mL}$ of methanol containing internal standard. Vesicles were shaken for 25 minutes at room temperature. Vesicle extracts were transferred to 96-well polypropylene deep-well plates by centrifugation and dried down under nitrogen. Samples were reconstituted in 50:50 (v:v) methanol:water prior to injection onto a LC-MS/MS system. Percent activity values were exported into GraphPad Prism to estimate $\mathrm{IC}_{50}$ values.

$(\mathrm{MDR} 1=$ Multi drug resistant AKA P-glycoprotein; BCRP $=$ Breast cancer resistant protein $)$ 
Plasma protein, liver microsome, and liver S9 binding

Frozen plasma in $\mathrm{K}_{3}$ EDTA was purchased from BioIVT and Dulbecco's phosphate buffered saline (DPBS) and $\mathrm{HCl}$ were purchased from Sigma. Fraction unbound was determined by equilibrium dialysis using an HTD 96 device (HTDialysis, LLC, Gales Ferry, CT) assembled with 12-14k MWCO membranes. Plasma was thawed and adjusted to $\mathrm{pH} 7.4$ with $1 \mathrm{~N} \mathrm{HCl}$ prior to use. Dialysis chambers were loaded with $150 \mu \mathrm{L}$ plasma and $150 \mu \mathrm{L}$ PBS in the donor and receiver chambers, respectively. Human liver microsomes were diluted to a concentration of $0.8 \mathrm{mg} / \mathrm{mL}$ in $100 \mathrm{mM}$ potassium phosphate buffer, donor chambers were loaded with $150 \mu \mathrm{L}$ diluted HLM and receiver chambers $150 \mu \mathrm{L}$ potassium phosphate buffer. Human liver S9 was diluted to a concentration of $0.03 \mathrm{mg} / \mathrm{mL}$ in $100 \mathrm{mM}$ potassium phosphate buffer, donor chambers were loaded with $150 \mu \mathrm{L}$ diluted HLS9, and receiver chambers $150 \mu \mathrm{L}$ potassium phosphate buffer. The dialysis plate was sealed with a gas-permeable membrane and stored in a $37^{\circ} \mathrm{C}$ water-jacked incubator maintained at $75 \%$ relative humidity and $5 \% \mathrm{CO}_{2}$, on a $100 \mathrm{rpm}$ plate shaker. After a 6-hour incubation, samples were matrix-matched and quench by protein precipitation, followed by LC-MS analysis. A set of satellite samples was included to measure stability after a 6-hour incubation. Incubations were conducted with 4 to 12 replicates. Fu was calculated by dividing the analyte-to-internal standard peak area ratio or analyte concentration in the buffer sample by the signal in the donor sample, corrected for any dilution factors. The HLM binding measured at $1 \mathrm{mg} / \mathrm{mL}$ was adjusted to account for the HLM protein concentration $(2 \mathrm{mg} / \mathrm{mL})$ using a dilution equation ${ }^{52}$. All incubations had $>70 \%$ analyte recovery and $>70 \%$ stability in 6 hours.

Preclinical pharmacokinetic studies

All activities involving animals were carried out in accordance with federal, state, local and institutional guidelines governing the use of laboratory animals in research in an AAALAC accredited facility and were reviewed and approved by Pfizer's Institutional Animal Care and Use Committee.

Rat PK studies were done at Pfizer (Groton, CT) or BioDuro Pharmaceutical Product Development Inc. (Shanghai, PRC); Jugular vein-cannulated male Wistar-Hannover rats were purchased from Charles River Laboratories, Inc. (Wilmington, MA) or Vital River (Beijing, China) and were typically 7-10 weeks of age at the time of dosing. During the pharmacokinetic studies all animals were housed individually. Access to food and water was provided ad libitum. Compounds were administered i.v. via the tail vein $(n=2$ or 3$)$, dosed as a $1 \mathrm{mg} / \mathrm{ml}$ solution using standard compatible excipients (PF 00835231, 2mL/kg or PF $7304814,1 \mathrm{~mL} / \mathrm{kg}$ ) for a resulting dose of $2 \mathrm{mg} / \mathrm{kg}$ PF 00835231 or $1.17 \mathrm{mg} / \mathrm{kg}$ PF 07304814 . Serial blood samples were collected via the jugular vein cannula at predetermined timepoints after dosing. Animals were monitored for pain or distress throughout the study, with at least daily monitoring during normal husbandry prior to study start. At the completion of the study, animals were euthanized by overdose of inhaled anesthesia followed by exsanguination. Blood samples were collected into tubes containing K3EDTA and stored on ice until centrifugation to obtain plasma, which was stored frozen at $-20{ }^{\circ} \mathrm{C}$ or lower. Urine samples were collected at room temperature and stored frozen at $20^{\circ} \mathrm{C}$ or lower at the end of each time interval.

Dog PK studies were done at Pfizer (Groton, CT); animal care and in vivo procedures were conducted according to guidelines from the Pfizer Institutional Animal Care and Use Committee. Male Beagle dogs were purchased from Marshall BioResources (North Rose, New 
York) and were typically 1-5 years of age at the time of dosing. Compounds were administered i.v. via the cephalic vein $(\mathrm{n}=2)$, dosed as a $2 \mathrm{mg} / \mathrm{ml}$ solution using standard compatible excipients (PF 00835231, 0.5mL/kg or PF $7304814,0.5 \mathrm{~mL} / \mathrm{kg}$ ) for a resulting dose of $1 \mathrm{mg} / \mathrm{kg}$ PF 00835231 equivalents or $1.17 \mathrm{mg} / \mathrm{kg}$ PF 07304814 . Serial blood samples were collected via the jugular vein at predetermined timepoints after dosing. Animals were monitored for pain or distress throughout the study, with at least daily monitoring during normal husbandry prior to study start. Blood samples were collected into tubes containing K3EDTA and stored on ice until centrifugation to obtain plasma, which was stored frozen at $-20^{\circ} \mathrm{C}$ or lower. Urine samples were collected at room temperature and stored frozen at $-20^{\circ} \mathrm{C}$ or lower at the end of each time interval.

Non-human primate PK studies were conducted at Pfizer (Groton, CT); All procedures performed on the animals were in accordance with regulations and established guidelines and were reviewed and approved by an Institutional Animal Care and Use Committee through an ethical review process. Male Cynomolgus monkeys were purchased from Covance (Princeton, NJ), Charles River Laboratories, Inc. (Wilmington, MA), or Envigo Global Services (Indianapolis, IN); animals 3-8 years of age were used in PK studies. Compounds were administered i.v. via the saphenous or cephalic vein $(n=2)$, dosed as a $1 \mathrm{mg} / \mathrm{ml}$ solution using standard compatible excipients (PF 00835231, 1mL/kg or PF $7304814,0.5 \mathrm{~mL} / \mathrm{kg}$ ) for a resulting dose of $1 \mathrm{mg} / \mathrm{kg}$ PF 00835231 or $1.17 \mathrm{mg} / \mathrm{kg}$ PF 07304814 . PF-00835231 was also administered via oral gavage $(\mathrm{n}=2)$ as a $1 \mathrm{mg} / \mathrm{ml}$ suspension in $0.5 \%$ methylcelluose $(\mathrm{w} / \mathrm{v})$ in water, at a dose volume of $5 \mathrm{~mL} / \mathrm{kg}$, for a final dose of $5 \mathrm{mg} / \mathrm{kg}$. Serial blood samples were collected via the femoral vein at predetermined timepoints after dosing. Animals were monitored for pain or distress throughout the study, with at least daily monitoring during normal husbandry prior to study start. Blood samples were collected into tubes containing K3EDTA and stored on ice until centrifugation to obtain plasma, which was stored frozen at $-20^{\circ} \mathrm{C}$ or lower. Urine samples were collected at room temperature and stored frozen at $-20^{\circ} \mathrm{C}$ or lower at the end of each time interval.

Plasma and urine samples were processed using protein precipitation with acetonitrile:methanol containing internal standard propranolol $(50 \mathrm{ng} / \mathrm{ml})$ followed by quantitation against a standard curve $(0.1-2500 \mathrm{ng} / \mathrm{ml})$ prepared in blank plasma .

Pharmacokinetic parameters were calculated using noncompartmental analysis (Watson v.7.5, Thermo Scientific). The area under the plasma concentration-time curve from $t=0$ to infinity (AUCinf) was estimated using the linear trapezoidal rule. Plasma clearance (CLp) was calculated as the i.v. dose divided by AUCinf. The terminal rate constant (kel) was calculated by linear regression of the terminal phase of the log-linear concentration-time curve and the terminal elimination t $1 / 2$ was calculated as 0.693 divided by kel. Apparent steady state distribution volume (Vdss) was determined by clearance multiplied by mean residence time. Percent excreted in urine was calculated as the amount of analyte in the urine divided by the amount dosed. Oral bioavailability was defined as the dose-normalized AUC after oral administration divided by the dose-normalized AUC after i.v. administration. Percent conversion of prodrug to active metabolite was calculated by dividing the dose-normalized PF00835231 AUCinf after i.v. dosing of prodrug PF-07304814 by the AUCinf after i.v. dosing of PF-00835231 incorporating their respective differences in molecular weight.

Bioanalytical LC-MS analysis 
Metabolic profiling samples were analyzed by ultrahigh-performance liquid chromatography coupled to UV spectrometry and high-resolution mass spectrometry (UHPLC-UV-HRMS). The system consisted of a Thermo Accela quaternary HPLC pump (Waltham, MA), Thermo Accela diode array UV/VIS detector, and CTC Analytics autoinjector (Zwingen, Switzerland), hyphenated with a Thermo Orbitrap Elite high-resolution mass spectrometer. Samples $(0.01 \mathrm{~mL})$ were injected onto a Phenomenex XB-C18 column $(2.1$ x 100mM, $2.6 \mu \mathrm{m})$ (Torrance, CA) maintained at $45^{\circ} \mathrm{C}$, at a flow rate of $0.4 \mathrm{~mL} / \mathrm{min}$. The mobile phase components were $\mathrm{A}: 0.1 \%$ formic acid in water and $\mathrm{B}$ : acetonitrile. The initial mobile phase composition of $5 \% \mathrm{~B}$ was held for 0.5 minutes followed by sequential linear gradients to $70 \% \mathrm{~B}$ at 11 minutes and $95 \% \mathrm{~B}$ at 13 minutes. This composition was held for 1 minute followed by re-equilibration at initial conditions for 1 minute. The eluent was passed through the UV detector (scanning from 200$400 \mathrm{~nm}$ ) before introduction into the mass spectrometer. The mass spectrometer was operated in positive mode with ion source temperatures, potentials, and gas flow settings adjusted to optimize the signal for PF-00835231.

LC-MS analysis of remaining PF-00835231 and PF-07304814 samples was typically performed using tandem liquid chromatography-mass spectrometry (LC-MS/MS) with a Sciex Triple Quad 5500 or 6500 mass spectrometer (Sciex, Framingham, MA), equipped with electrospray sources and Agilent 1290 binary pump (Santa Clara, CA). Aqueous mobile phase (A) was comprised of $1.0 \%$ formic acid in water and organic mobile phase (B) consisted of 1.0\% formic acid in acetonitrile. Ten $\mu 1$ of sample was injected onto an Acquity UPLC BEH C18 (2.1 x 50mm, $1.7 \mu \mathrm{m})$ (Waters Corporation, Milford, MA) or Halo C18 (2.1 x 30mm, $2.7 \mu \mathrm{m})$ (Advanced Materials, Wilmington, DE) column at room temperature with a flow rate of 0.5 $\mathrm{mL} / \mathrm{min}$. The gradient program began with $5 \%$ initial mobile phase B held for 0.3 minutes, followed by a linear gradient to $95 \%$ B over 2 minutes, held at $95 \%$ B for 0.3 minutes followed by re-equilibration to initial conditions for 0.6 minutes. MS was operated in multiple reaction monitoring (MRM) mode, in positive detection mode, with the following mass transitions and collision energies: PF-00835231 473.2/187.0 (CE 16), PF-07304814 553.1/267 (CE 24), propranolol 260.2/116.2 (CE 30), and indomethacin 358.1/139.0 (CE 27).

CYP inhibition samples were analyzed using MRM in positive ion mode. $1 \mathrm{~A} 2$ reactions were analyzed for acetaminophen 152.1/110.0 and $\left[{ }^{2} \mathrm{H}_{7}\right]$-acetaminophen 159.0/115.0 (CE 22) using a Phenomonex Synergi Hydro-RP column $(2 \times 30 \mathrm{~mm}, 2.5 \mu \mathrm{m}) .2 \mathrm{~B} 6$ reactions were analyzed for hydroxybupropion 256.0/139.0 and $\left[{ }^{2} \mathrm{H}_{6}\right]$-hydroxybupropion 262.0/139.0 (CE 31) using a Halo C18 column $(2.1 \times 30 \mathrm{~mm}, 2.7 \mu \mathrm{m})$. 2C8 reactions were analyzed for $\mathrm{N}$-desethylamodiaquine 328.2/283.0 and $\left[{ }^{2} \mathrm{H}_{5}\right]-\mathrm{N}$-desethylamodiaquine 333.2/283.0 (CE 23) using a Phenomenex Synergi Hydro-RP column $(2 \times 30 \mathrm{~mm}, 2.5 \mu \mathrm{m})$. 2C9 reactions were analyzed for 4'hydroxydiclofenac 213.0/266.0 and $\left[{ }^{13} \mathrm{C}_{6}\right]-4$ '-hydroxydiclofenac 318.0/272.0 (CE 20) using a Halo C18 column $(2.1 \times 30 \mathrm{~mm}, 2.7 \mu \mathrm{m})$. 2C19 reactions were analyzed for 4'hydroxymephenytoin 235.2/150.1 and $\left[{ }^{2} \mathrm{H}_{3}\right]$ - 4'-hydroxymephenytoin 238.1/150.1 (CE 26) using a Halo C18 column $(2.1 \times 30 \mathrm{~mm}, 2.7 \mu \mathrm{m})$. $2 \mathrm{D} 6$ reactions were analyzed for dextrorphan 258.1/201.1 and $\left[{ }^{2} \mathrm{H}_{3}\right]$-dextrorphan 261.0/201.1 (CE 31) using a Halo C18 column (2.1x30mm, $2.7 \mu \mathrm{m}) .3 \mathrm{~A} 4$ reactions were analyzed for 1 '-hydroxymidazolam $342.1 / 324.0$ and $\left[{ }^{2} \mathrm{H}_{4}\right]-1^{\prime}-$ hydroxymidazolam 346.1/328.0 (CE 30) using a Halo C18 column $(2.1 \times 30 \mathrm{~mm}, 2.7 \mu \mathrm{m})$ or $6 \beta$ hydroxytestosterone 305.2/269.2 and $\left[{ }^{2} \mathrm{H}_{3}\right]-6 \beta$-hydroxytestosterone 308.2/272.7 (CE 25) using a Halo C18 column $(2.1 \times 50 \mathrm{~mm}, 2.0 \mu \mathrm{m})$.

Analyst software was used to measure peak areas and peak area ratios of analyte to internal standard were calculated. A calibration curve was constructed from the peak area ratios (analyte 
to internal standard) with a weighted linear $\left(1 / \mathrm{x}^{2}\right)$ regression, from which unknown samples concentrations were calculated.

Human pharmacokinetic predictions

Scaling in vitro human liver microsomal or liver S9 apparent CLint to in vivo CLint.

$$
\text { Microsomal or Liver S9 CLintu, in vivo }=S F\left(\frac{C L i n t, a p p \cdot P R p L W \cdot L W p B W}{f u, i n c}\right)(9)
$$

CLint, app = apparent intrinsic clearance, $\mathrm{PRpLW}=$ Microsomal or S9 protein per liver weight (45 or $121 \mathrm{mg} / \mathrm{g}$ respectively), PRpLW = liver weight per bodyweight $(21 \mathrm{~g} / \mathrm{kg}$ ), fu,inc = HLM or S9 unbound fraction, SF = Pfizer scaling factor (x1.3 for HLM, x1 for S9)

Scaling in vivo CLint to human plasma clearance.

$$
\text { Human CLh }=\frac{C \text { Lintu } \cdot f u, p \cdot Q h}{\left(\text { CLintu } \cdot f u \cdot p /_{R b p}+Q h\right)}
$$

$\mathrm{CLintu}=$ scaled in vivo intrinsic clearance, fu,p =plasma fu, $\mathrm{Qh}=$ hepatic blood flow $(20$ $\mathrm{mL} / \mathrm{min} / \mathrm{kg}$ ), $\mathrm{Rbp}=$ in vitro blood to plasma ratio

Prediction of PF-00835231 human Vdss.

$$
\text { Human Vdss }=\text { human } f u, p \cdot\left(\frac{\text { animal } V d s s}{\text { animal } f u, p}\right)
$$

Calculation of predicted human half-life.

$$
\text { Human half life }=\text { human } f u, p \cdot\left(\frac{0.693 \cdot \text { human } V d s s}{\text { human } C L_{h}}\right)
$$

Calculation of human dose.

$$
\text { Dose }=\left(\operatorname{CLp}(a c t) \cdot\left(\frac{\operatorname{Css}(\mathrm{act})}{f m(a c t)}\right)\right) / \frac{M W(a c t)}{M W(\text { pro })}(13)
$$

Rearranged from published equation factoring in MW differences ${ }^{53}$. act $=$ PF-00835231, pro $=$ PF-07304814, CLp = plasma clearance, $\mathrm{Css}=$ steady state concentration, $\mathrm{fm}=\%$ conversion from PF-07304814 to PF-00835231, MW = molecular weight $(\mathrm{PF}-07304814=552.5$, PF$00835231=472.5$ )

Physiologically-based pharmacokinetic (PBPK) modeling of PF-00835231

A commercially available dynamic PBPK model, Simcyp population-based simulator (version 18.2; Certara UK Limited, Simcyp Division, Sheffield, United Kingdom), was used in the 
present study ${ }^{54}$. Physicochemical and pharmacokinetic parameters of PF-00835231 for the PBPK models are summarized in Table S10. Since PF-07304814 (prodrug) was predicted to be converted to PF-00835231 rapidly and extensively in vivo, the simulation was performed assuming an intravenous infusion of PF-00835231 with the conversion efficiency of $75 \%$ from PF-07304814, which was predicted from animal data. For the prediction of DDIs of PF00835231 with itraconazole, the vendor-verified compound files in Simcyp library were used, i.e., itraconazole (sv-itraconazole_fed capsule) with competitive $\mathrm{K}_{\mathrm{i}}=0.0013 \mu \mathrm{M}$ and itraconazole metabolite (sv-OH-itraconazole) with competitive $\mathrm{K}_{\mathrm{i}}=0.0023 \mu \mathrm{M}$.

Simulation of clinical trials was performed with a virtual population of healthy volunteers in 10 trials of 10 subjects (total 100 subjects), each aged 20 to 50 years with a female/male ratio of 0.5 , whose CYP3A4 degradation rate constant $\left(k_{d e g}\right)$ was $0.019 \mathrm{~h}^{-1}$ in liver and $0.030 \mathrm{~h}^{-1}$ in intestine. The output sampling interval in Simcyp simulation toolbox was set to 0.2 hours in all simulations. To predict DDIs of PF-00835231 with itraconazole, PF-00835231 at 320mg/day (equivalent to PF-00835231 formed following PF-07304814 500mg/day taking into account conversion and molecular weight differences) was administered IV for 10 days (days 5 to 15) to a virtual population with and without 15-day repeated oral administration of itraconazole 200mg once daily (days 1 to 15). Pharmacokinetic parameters such as maximal plasma concentration $\left(\mathrm{C}_{\max }\right)$, area under the plasma concentration time-curve from time zero to 24 hours post dose (AUC) and the ratios of $\mathrm{C}_{\max }\left(\mathrm{C}_{\max } \mathrm{R}\right)$ and $\mathrm{AUC}$ (AUCR) in treatment groups relative to control groups were obtained from Simcyp outputs.

The model-predicted $\mathrm{C}_{\max } \mathrm{R}$ and AUCR for PF-00835231 were $\sim 2 \mathrm{x}$ at the daily dose of 320mg/day (corresponding to 500mg/day PF-07304814) (Table S11).

\section{Ceff projection of protease inhibitor to the clinic}

The inhibitory quotient (IQ) has been a useful metric for translating preclinical antiviral potencies to the clinic across a number of viral diseases as indicated in the FDA guidance ${ }^{55}$. IQ is defined as the human $\mathrm{C}_{\min , \mathrm{u}}$ unbound concentration divided by the in vitro unbound (serum adjusted) $\mathrm{EC}_{50, \mathrm{u}}$ value in the antiviral assay (equation 14).

$$
I Q=\frac{C_{\min , u}}{E C_{50, u}}(14)
$$

Some antiviral therapies have shown significant benefit with IQ close to $1^{56}$; however, rapidly controlling viral replication frequently requires maintaining an exposure at least 10x higher than in vitro $\mathrm{EC}_{50} 0^{30}$. Clinically approved protease inhibitors have effectively decreased viral loads when dosed at IQ values from 1-100, when protein binding and site of action exposure are taken into account ${ }^{30}$. Importantly, antivirals in general and, specifically, protease inhibitors can potentially lead to increased mutations and additional drug resistance when dosed at an IQ less than $1^{57}$.

How high an IQ value is required depends on the steepness of the dose response curve. The hill coefficient $(\mathrm{m})$, and the $\mathrm{EC}_{50}$ are related to the in vitro antiviral activity at a range of concentrations $(\mathrm{C})$ by equation 15 :

$$
\text { in vitro antiviral activity }=100 * \frac{C^{m}}{E C_{50}^{m}+C^{m}}
$$


PF-00835231 shows a high hill coefficient $(\mathrm{m}=3)$ across a range of in vitro antiviral assays, like those of clinical protease inhibitors targeting HIV and $\mathrm{HCV}^{21,58}$. There is only a 2- to 3-fold difference between the antiviral $\mathrm{EC}_{50}$ and $\mathrm{EC}_{90}$ concentrations (Fig. 2), rather than the typical 9fold difference for antiviral agents with hill coefficients of 1 . Therefore, relatively small ratios of exposure to $\mathrm{EC}_{50}$ values (3-10) are related to near complete viral suppression.

\section{$\underline{\text { Rat 24-hour continuous intravenous infusion GLP toxicity study }}$}

The study was conducted by Charles River Laboratories for Pfizer Inc, in accordance with the U.S. Department of Health and Human Services, Food and Drug Administration, United States Code of Federal Regulations, Title 21, Part 58: Good Laboratory Practice for Nonclinical Laboratory Studies. Briefly, 8-week old male and female Sprague-Dawley rats $(n=15$ per sex per group) implanted with femoral catheters exteriorized between the scapulae were assigned to vehicle, or PF-07304814 dose groups $(80,360$ and $1000 \mathrm{mg} / \mathrm{Kg})$. The vehicle and test article were administered once on Day 1 as a 24-hour continuous IV infusion at a rate of 2.5 $\mathrm{mL} / \mathrm{Kg} /$ hour. Main group rats ( $\mathrm{n}=10$ per sex per group) were euthanized on Day 2 and recovery/delayed toxicity group ( $n=5$ per sex per group) on Day 14 . Study evaluations included detailed clinical observations, body weights, food consumption, functional observation battery, clinical pathology, toxicokinetics, and gross and microscopic pathology.

Rat 4-day continuous intravenous infusion, exploratory nonGLP toxicity study

The study was conducted with Pfizer Worldwide R \& D, and due to the exploratory nature of this study, compliance with GLP regulations was not required. Male Sprague-Dawley rats ( $\mathrm{n}=3$ per group) were administered either vehicle or PF-00835231 (at 24.6 and 246mg/kg/day) by continuous intravenous infusion via a femoral venous catheter for 4 days, followed by necropsies on Day 5. Study evaluations included clinical observations, body weights, clinical pathology, toxicokinetics, gross pathology and microscopic pathology (control and high dose groups only).

\section{Bacterial reverse mutation assays}

PF-00835231 and PF-07304814 were tested to evaluate their mutagenic potential by measuring their ability to induce reverse mutations at selected loci of several strains of Salmonella typhimurium and at the tryptophan locus of E. coli strain WP2 uvrA in the presence and absence of an exogenous metabolic activation system using standard protocols ${ }^{59-61}$. These GLP studies were conducted by BioReliance Corporation for Pfizer Inc.

\section{Effect of PF-00835231 and PF-07304814 on hERG potassium channels}

The in vitro effects of PF-00835231 and PF-07304814 on the hERG (human ether-à-go-gorelated gene) channel current (a surrogate for $I_{K r}$, the rapidly activating delayed rectifier cardiac potassium current ${ }^{62}$ were tested using standard protocols. This channel has been selected for evaluation because inhibition of $I_{K r}$ is the most common cause of cardiac action potential prolongation by non-cardiac drugs ${ }^{63-65}$. Increased action potential duration causes prolongation of the QT interval and has been associated with a dangerous ventricular arrhythmia, torsade de pointes $^{63}$. The concentration-response relationship of the effect of PF-00835231 and PF07304814 on the hERG potassium channel current was evaluated at near-physiological temperature in stably transfected mammalian cells that express the hERG gene using standard protocols. These GLP studies were conducted by Charles River Laboratories for Pfizer Inc. 


\section{Secondary/off-target pharmacology}

Secondary pharmacology studies were conducted by Eurofins Cerep on behalf of Pfizer Inc. The in vitro off-target pharmacology of PF-07304814 and PF-00835231 was individually assessed at $100 \mu \mathrm{M}$ in a broad target profiling panel which represents targets with known links to potential safety concerns and includes G-protein coupled receptors, ion channels, transporters, and enzymes according to established protocols.

\section{$\underline{\text { Hemocompatibility studies }}$}

The effects of PF-07304814 and PF-00835231 on human red blood cell hemolysis and plasma flocculation were evaluated in GLP-compliant studies conducted by Charles River Laboratories on behalf of Pfizer Inc. Briefly, whole blood samples from human volunteers were incubated with a range of concentrations of PF-07304814 and PF-00835231 (in relevant vehicles) and hemolysis was evaluated by determination of whole blood hematocrit, whole blood hemoglobin concentration, plasma hemoglobin concentration, plasma hemolytic index, and visual macroscopic hemolysis assessment. Flocculation was evaluated by determination of the plasma turbidity index and visual flocculation assessment. 
<smiles>COc1cccc2[nH]c(C(=O)N[C@@H](CC(C)C)C(=O)NC(CC3CCNC3=O)C(=O)CO)cc12</smiles>

1<smiles>COc1cccc2[nH]c(C(=O)N[C@@H](CC(C)C)C(=O)NC(CC(=O)COP(=O)(OC(C)(C)C)OC(C)(C)C)CC3CCNC3=O)cc12</smiles>

2<smiles>COc1cccc2[nH]c(C(=O)N[C@@H](CC(C)C)C(=O)NC(CC3CCNC3=O)C(=O)OP(=O)(O)O)cc12</smiles>

Fig. S1. Synthesis of PF-07304814 and PF-00835231 with reagents and conditions. a) Ditert-butyl N,N-dipropan-2-ylphosphoramidite, tetrazole, tetrahydrofuran, $0^{\circ} \mathrm{C}$ to room temp., then $\mathrm{H} 2 \mathrm{O} 2,0^{\circ} \mathrm{C}, 91 \%$ over 2 steps; b) $\mathrm{CF} 3 \mathrm{COOH}, \mathrm{CH} 2 \mathrm{Cl} 2,0^{\circ} \mathrm{C}, 54 \%$. 

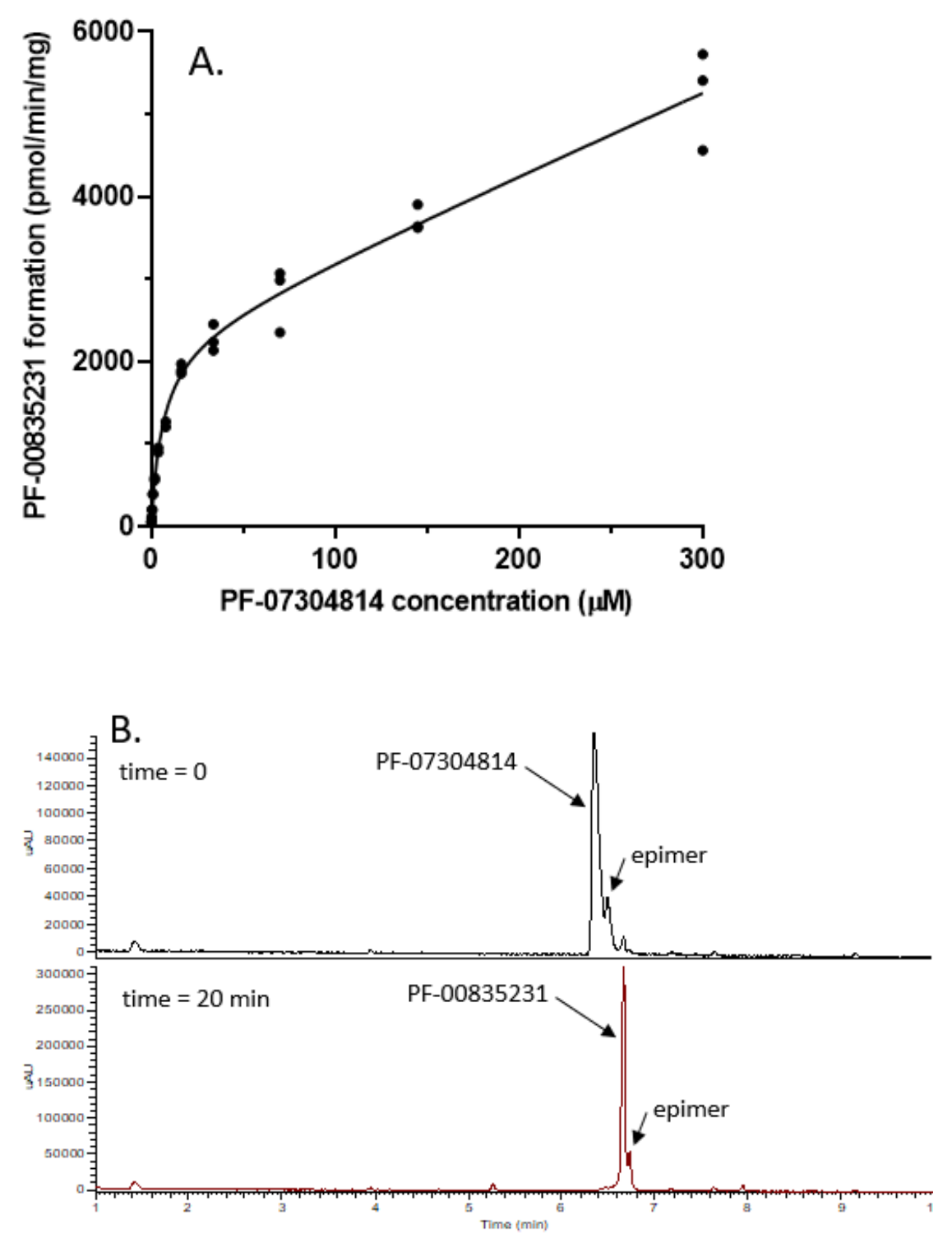

Fig. S2. Metabolism of PF-07304814 in human liver S9 (A) Substrate saturation plot of the metabolism of phosphate prodrug PF-07304814 to the active drug PF-00835231 in human liver S9 fraction. (B) HPLC-UV chromatograms of extracts of an incubation of phosphate prodrug PF07304814 (Rt $6.3 \mathrm{~min}$ ) in human liver S9 demonstrating complete conversion to the active entity PF-00835231 (Rt 6.7 min). 
Table S1. Summary of the In Vitro Antiviral Activity for PF-00835231 on Related Coronaviruses in Vero E6 cells with Efflux Inhibitor

\begin{tabular}{|c|c|c|c|c|}
\hline Drug Treatment & $\begin{array}{c}\text { EC50 } \\
\text { SARS-CoV-2 } \\
\boldsymbol{\mu M} \pm \text { Std. Dev }\end{array}$ & $\begin{array}{c}\text { EC50 } \\
\text { MERS } \\
\boldsymbol{\mu M} \pm \text { Std. Dev }\end{array}$ & $\begin{array}{c}\text { EC50 } \\
\text { SARS-CoV-1 } \\
\boldsymbol{\mu M} \pm \text { Std. Dev }\end{array}$ & $\begin{array}{c}\text { EC50 } \\
\text { MA-15 } \\
\boldsymbol{\mu M} \pm \text { Std. Dev }\end{array}$ \\
\hline $\begin{array}{c}\text { PF-00835231 } \\
+2 \mu \mathrm{M} \text { EI }\end{array}$ & $0.06 \pm 0.03$ & $0.04 \pm 0.01$ & $0.09 \pm 0.04$ & $0.08 \pm 0.01$ \\
\hline
\end{tabular}

EI = efflux inhibitor (CP-00100356); Std. Dev. = standard deviation; N=3 for SARS-CoV-2 and MERS:

$\mathrm{N}=2$ for SARS-CoV-1 and MA-15

Table S2. Activity of PF-00835231 against human proteases and HIV protease.

\begin{tabular}{ll}
\hline Protease & IC50 $\boldsymbol{\mu M}$ \\
\hline SAR-Cov-2 3CLpro & 0.0069 \\
Human Cathepsin B & 6.1 \\
Human Elastase & $>33$ \\
Human Chymotrypsin & $>100$ \\
Human Thrombin & $>100$ \\
Human Caspase 2 & $>33$ \\
Human Cathepsin D & $>11$ \\
HIV-1 protease & $>11$ \\
\hline
\end{tabular}


bioRxiv preprint doi: https://doi.org/10.1101/2020.09.12.293498; this version posted February 12, 2021. The copyright holder for this preprint (which was not certified by peer review) is the author/funder. All rights reserved. No reuse allowed without permission. 
Table S3. Evaluation of the fractional metabolism of PF-00835231 in human liver microsomes and recombinant CYP3A using selective CYP3A inhibitor ketoconazole.

\begin{tabular}{c|c|c|c|c|c|c}
\hline Metabolite & $\mathbf{K}_{\mathbf{M}}(\boldsymbol{\mu M})$ & $\begin{array}{c}\mathbf{V}_{\mathbf{m a x}} \\
(\mathbf{p m o l} / \mathbf{m i n} / \mathbf{m g})\end{array}$ & $\begin{array}{c}\mathbf{C L}_{\text {int }} \\
(\boldsymbol{\mu L} \mathbf{L} \mathbf{m i n} / \mathbf{m g})\end{array}$ & $\mathbf{f}_{\mathbf{C L}}$ & $\begin{array}{c}\text { \% Inhibition } \\
\mathbf{b y} \\
\text { ketoconazole }\end{array}$ & $\begin{array}{c}\mathbf{f}_{\mathbf{m}} \\
(\mathbf{C Y P 3 A})\end{array}$ \\
\hline Metabolite 1 & 124 & 321 & 2.6 & 0.61 & 86 & 0.53 \\
Metabolite 2 & 119 & 91 & 0.76 & 0.18 & 90 & 0.16 \\
Metabolite 3 & 120 & 68 & 0.57 & 0.13 & 82 & 0.11 \\
Metabolite 4 & 43 & 12 & 0.30 & 0.07 & 82 & 0.06 \\
\hline Sum & & & $\mathbf{4 . 2}$ & & & $\mathbf{0 . 8 6}$ \\
\hline
\end{tabular}

$\mathrm{CL}_{\text {int }}=$ Intrinsic clearance; $\mathrm{CYP}=$ Cytochrome P450; $\mathrm{fL}=$ Fractional clearance; $\mathrm{fm}_{\mathrm{m}}=$ Fraction metabolized; HLM = Human liver microsomes; $\mathrm{K}_{\mathrm{M}}=$ Concentration at $50 \%$ maximum velocity; $\mathrm{rCYP}=$ Recombinant human $\mathrm{CYP} ; \mathrm{V}_{\max }=\mathrm{Maximum}$ initial velocity. 
Table S4. Reversible CYP inhibition by PF-07304814 or PF-00835231 in human liver microsomes using individual CYP substrates in the presence of NADPH.

\begin{tabular}{|c|c|c|c|c|c|}
\hline \multirow{3}{*}{ CYP } & \multirow{3}{*}{ Enzyme Reaction } & \multicolumn{2}{|c|}{\begin{tabular}{|c|} 
Zero-Minute \\
Preincubation $\left(\mathbf{T}_{\mathbf{0}}\right)^{\mathrm{a}}$ \\
\end{tabular}} & \multicolumn{2}{|c|}{$\begin{array}{c}\text { 30-Minute Preincubation } \\
\left(\mathrm{T}_{30}\right)^{\mathrm{a}}\end{array}$} \\
\hline & & PF-07304814 & PF-00835231 & $\begin{array}{c}\text { PF- } \\
\text { 07304814 }\end{array}$ & PF-00835231 \\
\hline & & $\mathrm{IC}_{50}(\boldsymbol{\mu M})$ & $\mathrm{IC}_{50}(\mu \mathrm{M})$ & $\mathrm{IC}_{50}(\mu \mathrm{M})$ & $\mathrm{IC}_{50}(\boldsymbol{\mu M})$ \\
\hline $1 \mathrm{~A} 2$ & $\begin{array}{c}\text { Phenacetin } \\
\text { O-dealkylation }\end{array}$ & $>100$ & $>200$ & $>100$ & $>200$ \\
\hline 2B6 & $\begin{array}{c}\text { Bupropion } \\
\text { hydroxylation }\end{array}$ & ND & $>200$ & ND & $>200$ \\
\hline $2 \mathrm{C} 8$ & $\begin{array}{c}\text { Amodiaquine N- } \\
\text { dealkylation }\end{array}$ & $>100$ & $>200$ & $>100$ & $>200$ \\
\hline 2C9 & $\begin{array}{c}\text { Diclofenac } \\
\text { 4'-hydroxylation }\end{array}$ & $>100$ & $>200$ & $>100$ & $>200$ \\
\hline $2 \mathrm{C} 19$ & $\begin{array}{c}\text { S-Mephenytoin } \\
\text { 4'-hydroxylation }\end{array}$ & $>100$ & $>200$ & $>100$ & $>200$ \\
\hline 2D6 & $\begin{array}{c}\text { Dextromethorphan } \\
\text { O-demethylation }\end{array}$ & $>100$ & $>200$ & $>100$ & $>200$ \\
\hline $3 \mathrm{~A} 4 / 5$ & $\begin{array}{c}\text { Midazolam } \\
\text { 1'-hydroxylation }\end{array}$ & $>100$ & $>200$ & $>100$ & $>200$ \\
\hline $3 \mathrm{~A} 4 / 5$ & $\begin{array}{c}\text { Testosterone } 6 \beta- \\
\text { hydroxylation }\end{array}$ & ND & $108(70-172)$ & ND & $62.4(41-98)$ \\
\hline
\end{tabular}

Confidence interval shown in parenthesis; $\mathrm{CYP}=$ Cytochrome $\mathrm{P} 450 ; \mathrm{IC}_{50}=50 \%$ inhibitory concentration; $\mathrm{NADPH}=$ Reduced form of nicotinamide adenine dinucleotide phosphate; $\mathrm{NC}=$ Not calculated $\mathrm{ND}=\mathrm{Not}$ determined, TDI $=$ Time-dependent inhibition; $\mathrm{T}_{0}=$ Time zero; $\mathrm{T}_{30}=$ Time 30 minutes .

${ }^{a}$ Average data obtained from triplicate samples for each test article concentrations were used to calculate $\mathrm{IC}_{50}$ values. 
Table S5. Time dependent CYP3A4/5 inhibition by PF-00835231 in human liver microsomes using individual CYP substrates.

\begin{tabular}{|c|c|c|c|c|}
\hline CYP & $\begin{array}{c}\text { Probe Substrate } \\
(\text { Concentration) }\end{array}$ & $\begin{array}{c}\mathbf{k}_{\text {inact }} \pm \mathbf{S E} \\
\left(\mathbf{m i n}^{-1}\right)\end{array}$ & $\begin{array}{c}\mathbf{K}_{\mathbf{I}} \pm \mathbf{S E} \\
(\boldsymbol{\mu M})\end{array}$ & $\begin{array}{c}\mathbf{K}_{\text {inact }} / \mathbf{K}_{\mathbf{I}} \\
(\mathbf{m L} / \boldsymbol{\mu m o l} / \mathbf{m i n})\end{array}$ \\
\hline $3 \mathrm{~A} 4 / 5$ & Midazolam $(20 \mu \mathrm{M})$ & $\begin{array}{c}0.0300 \pm \\
0.0020\end{array}$ & $163 \pm 31$ & 0.184 \\
\hline $3 \mathrm{~A} 4 / 5$ & Testosterone $(386 \mu \mathrm{M})$ & $\begin{array}{c}0.0434 \pm \\
0.0007\end{array}$ & $168 \pm 8$ & 0.258 \\
\hline
\end{tabular}

CYP = Cytochrome P450; HLM = Human liver microsomes; $\mathrm{K}_{\mathrm{I}}=$ Apparent inactivation constant at half-maximal rate of inactivation; $k_{\text {inact }}=$ Maximal rate of enzyme inactivation; $\mathrm{k}_{\text {inact }} / \mathrm{K}_{\mathrm{I}}=$ Measure of inactivator efficiency; $\mathrm{NADPH}=\mathrm{Reduced}$ form of nicotinamide adenine dinucleotide phosphate; SE = Standard error; TDI = Time-dependent inhibition. 
Table S6. In vitro transporter inhibition by PF-07304814 or PF-00835231 using probe substrates.

\begin{tabular}{|c|c|c|c|}
\hline \multirow{2}{*}{ Transporter } & Probe Substrate $($ Concentration) & \multicolumn{2}{|c|}{ IC $_{\mathbf{5 0}}(\boldsymbol{\mu M})$} \\
\cline { 3 - 4 } & & PF-07304814 & PF-00835231 \\
\hline MDR1/P-gp & N-methyl quinidine $(0.2 \mu \mathrm{M})$ & $>300$ & 65.6 \\
\hline BCRP & Rosuvastatin $(0.2 \mu \mathrm{M})$ & 238 & 19.5 \\
\hline OATP1B1 & Rosuvastatin $(0.5 \mu \mathrm{M})$ & 134 & 30.1 \\
\hline OATP1B3 & Rosuvastatin $(0.5 \mu \mathrm{M})$ & 202 & 51.6 \\
\hline OCT1 & {$\left[{ }^{14} \mathrm{C}\right]$ Metformin $(10 \mu \mathrm{M})$} & $>300$ & 36.3 \\
\hline OAT1 & {$\left[{ }^{3} \mathrm{H}\right]$ PAH $(0.5 \mu \mathrm{M})$} & $>300$ & $>300$ \\
\hline OAT3 & {$\left[{ }^{3} \mathrm{H}\right] \mathrm{ES}(0.1 \mu \mathrm{M})$} & $>300$ & $>300$ \\
\hline OCT2 & {$\left[{ }^{14} \mathrm{C}\right]$ Metformin $(20 \mu \mathrm{M})$} & $>300$ & 175.1 \\
\hline MATE1 & {$\left[{ }^{14} \mathrm{C}\right]$ Metformin $(20 \mu \mathrm{M})$} & $>300$ & 179.8 \\
\hline MATE2K & {$\left[{ }^{14} \mathrm{C}\right]$ Metformin $(20 \mu \mathrm{M})$} & $>300$ & \\
\hline
\end{tabular}

$\mathrm{BCRP}=$ Breast cancer resistance protein; BSEP = Bile salt export pump; OAT = Organic anion transporter; $\mathrm{OATP}=$ Organic anion-transporting polypeptide; $\mathrm{OCT}=$ Organic cation transporter; $\mathrm{IC}_{50}=50 \%$ inhibitory concentration; MATE $=$ Multidrug and toxin extrusion protein; $\mathrm{MDR}=$ Multidrug resistance protein; $\mathrm{PAH}=\mathrm{P}$-aminohippuric acid P-gp $=$ P-glycoprotein . 
Table S7. Plasma protein binding of PF-07304814 or PF-00835231 in plasma, liver microsomes and S9.

\begin{tabular}{|c|c|c|c|}
\hline \multirow{2}{*}{ Species } & \multirow{2}{*}{ Matrix } & \multicolumn{2}{|c|}{ Unbound fraction fu (\%CV) } \\
\cline { 2 - 4 } & & PF-07304814 $^{\mathbf{d}}$ & PF-00835231 \\
\hline Human & Liver microsomes $^{\mathrm{a}, \mathrm{c}}$ & ND & $0.75(8.7)$ \\
\hline Human & Liver S9, & $0.890(1.9)$ & ND \\
\hline Human & Plasma & $0.184(5.9)$ & $0.449(7.5)$ \\
\hline Monkey & Plasma & $0.361(10.2)$ & $0.441(7.7)$ \\
\hline Dog & Plasma & $0.312(10.9)$ & $0.416(9.5)$ \\
\hline Rat & Plasma & $0.379^{\mathrm{f}}(12.7)$ & $0.327^{\mathrm{g}}(12.1)$ \\
\hline
\end{tabular}

${ }^{\text {a }}$ measured at $0.8 \mathrm{mg} / \mathrm{mL}$ protein, ${ }^{\text {b }}$ measured at $0.03 \mathrm{mg} / \mathrm{mL}$ protein, ${ }^{c} 2 \mu \mathrm{M}$ substrate concentration, ${ }^{\mathrm{d}} 3.4 \mu \mathrm{M}$ substrate concentration, ${ }^{\mathrm{e}} 5 \mu \mathrm{M}$ substrate concentration, ${ }^{\mathrm{f}}$ Sprague-Dawley rat plasma, ${ }^{\mathrm{g}} \mathrm{W}$ istar Hannover rat plasma 
Table S8. Preclinical plasma PK summary of PF-07304814 or PF-00835231 following oral and/or IV administration to rats, dogs and monkeys.

\begin{tabular}{|c|c|c|}
\hline \multicolumn{3}{|c|}{ Rat PK Data following IV or oral administration } \\
\hline PK parameter & PF-07304814 (n=2) & PF-00835231 $(n=3)$ \\
\hline Dose & $1.17 \mathrm{mg} / \mathrm{kg}$ & $2 \mathrm{mg} / \mathrm{kg}(\mathrm{IV}+\mathrm{PO})$ \\
\hline $\mathrm{CL}(\mathrm{mL} / \mathrm{min} / \mathrm{kg})$ & $194(168-220)$ & $27.0 \pm 3.10$ \\
\hline Vdss $(\mathrm{L} / \mathrm{kg})$ & $0.58(0.57-0.59)$ & $0.75 \pm 0.24$ \\
\hline Terminal T1/2 (h) & $0.30(0.36-0.23)$ & $0.72 \pm 0.12$ \\
\hline Oral F\% & ND & $1.4 \pm 0.76$ \\
\hline \%unchanged in urine & $<0.1(<0.1-<0.1)$ & $7.8 \pm 11.5$ \\
\hline PF-00835231 AUCinf (ng.h/mL) & $424(366-481)$ & $1250 \pm 146$ \\
\hline \%Conversion to PF-00835231 & $68 \%(59-77)$ & - \\
\hline \multicolumn{3}{|c|}{ Dog PK Data following IV administration $(n=2)$} \\
\hline PK parameter & PF-07304814 & PF-00835231 \\
\hline Dose $(\mathrm{mg} / \mathrm{kg})$ & $1.17 \mathrm{mg} / \mathrm{kg}$ & $1.0 \mathrm{mg} / \mathrm{kg}(\mathrm{IV})$ \\
\hline CLp (mL/min/kg) & $517(301-733)$ & $18.2(15.9-20.5)$ \\
\hline Vdss $(\mathrm{L} / \mathrm{kg})$ & $9.3(5.8-12.9)$ & $1.1(0.9-1.2)$ \\
\hline Terminal T1/2 (h) & $0.5(0.3-0.7)$ & $1.5(1.4-1.6)$ \\
\hline \%unchanged in urine & $<0.1(<0.1-<0.1)$ & $4.8(1.6-8.0)$ \\
\hline PF-00835231 AUCinf (ng.h/mL) & $753(633-872)$ & $932(813-1050)$ \\
\hline \%Conversion to PF-00835231 & $81 \%(78-83)$ & - \\
\hline \multicolumn{3}{|c|}{ Monkey PK Data following IV or oral administration $(n=2)$} \\
\hline PK parameter & PF-07304814 & PF-00835231 \\
\hline Dose $(\mathrm{mg} / \mathrm{kg})$ & $1.17 \mathrm{mg} / \mathrm{kg}$ & $1.0 \mathrm{mg} / \mathrm{kg}(\mathrm{IV}), 5 \mathrm{mg} / \mathrm{kg} \mathrm{PO}$ \\
\hline $\mathrm{Cl}(\mathrm{mL} / \mathrm{min} / \mathrm{kg})$ & $191(129-252)$ & $28.7(27.1-30.2)$ \\
\hline Vdss (L/kg) & $1.8(0.91-2.6)$ & $1.4(1.3-1.5)$ \\
\hline Terminal T1/2(h) & $2.6(2.2-3.0)$ & $1.2(1.1-1.3)$ \\
\hline Oral F\% & ND & $<0.1(<0.1-<0.1)$ \\
\hline \%unchanged in urine & $<0.1(<0.1-<0.1)$ & $0.9(0.8-1.0)$ \\
\hline PF-00835231 AUCinf (ng.h/mL) & 447 (304-589) & 583 (614-552) \\
\hline \%Conversion to PF-00835231 & $76 \%(55-96)$ & - \\
\hline
\end{tabular}


Table S9. Metabolic stability and enzyme kinetics of PF-07304814 in liver S9.

\begin{tabular}{|c|c|c|c|c|}
\hline \multirow{2}{*}{$\begin{array}{c}\text { Kinetic } \\
\text { Parameters }\end{array}$} & \multicolumn{4}{|c|}{ Kinetics } \\
\hline & Rat & Dog & Monkey & Human \\
\hline Model & $\begin{array}{c}\text { Two Enzyme - } \\
\text { MM and } \\
\text { Unsaturable }\end{array}$ & $\begin{array}{c}\text { Two Enzyme - } \\
\text { MM and } \\
\text { Unsaturable }\end{array}$ & $\begin{array}{c}\text { Two Enzyme - } \\
\text { MM and } \\
\text { Unsaturable }\end{array}$ & $\begin{array}{c}\text { Two Enzyme - } \\
\text { MM and } \\
\text { Unsaturable }\end{array}$ \\
\hline $\mathrm{K}_{\mathrm{M}}(\mu \mathrm{M})$ & 53.4 & 2.91 & 8.10 & 6.23 \\
\hline $\begin{array}{l}\mathrm{V}_{\max } \\
(\mathrm{pmol} / \mathrm{min} / \mathrm{mg})\end{array}$ & 2188 & 214 & 1186 & 2313 \\
\hline $\begin{array}{l}\mathrm{CL}_{\text {int, } 2} \\
(\mu \mathrm{L} / \mathrm{min} / \mathrm{mg})\end{array}$ & 4.56 & 1.69 & 3.06 & 9.96 \\
\hline $\begin{array}{l}\mathrm{CL}_{\text {int,app }} \\
(\mu \mathrm{L} / \mathrm{min} / \mathrm{mg})\end{array}$ & 45.5 & 75.2 & 150 & 381 \\
\hline $\begin{array}{l}\text { CL } \mathrm{L}_{\text {intu }} \\
(\mu \mathrm{L} / \mathrm{min} / \mathrm{mg})\end{array}$ & 51 & 84 & 168 & 428 \\
\hline
\end{tabular}


Table S10. Physicochemical and pharmacokinetic parameters of PF00835231 for PBPK modeling.

\begin{tabular}{|c|c|c|}
\hline Parameter (units) & Value & Source \\
\hline Molecular weight & 472 & Calculated \\
\hline $\log P$ & 0.75 & Calculated \\
\hline $\mathrm{pK}_{\mathrm{a}}$ & neutral & Calculated \\
\hline $\mathrm{Rbp}$ & 0.8 & Measured in vitro \\
\hline$f_{\text {u,plasma }}$ & 0.449 & Measured in vitro \\
\hline $\mathrm{V}_{\mathrm{ss}}(\mathrm{L} / \mathrm{kg})$ & 1 & Predicted from animal data \\
\hline Kp scalar & 3.1 & Adjusted from the prediction (method 2) \\
\hline $\mathrm{CL}_{\text {plasma }}(\mathrm{L} / \mathrm{h})$ & 25 & Predicted from in vitro $\mathrm{CL}$ \\
\hline $\mathrm{f}_{\mathrm{m}, \mathrm{CYP} 3 \mathrm{~A}}$ & 0.76 & Predicted from in vitro phenotyping data \\
\hline $\begin{array}{l}\mathrm{rCL}_{\text {int,CYP3A4 }}(\mu \mathrm{L} / \mathrm{min} / \mathrm{pmol} \\
\mathrm{P} 450)\end{array}$ & 0.15 & Calculated by Simcyp (retrograde model) \\
\hline $\mathrm{CL}_{\mathrm{int}, \mathrm{HLM}}(\mu \mathrm{L} / \mathrm{min} / \mathrm{mg}$ protein $)$ & 6 & Calculated by Simcyp (retrograde model) \\
\hline $\mathrm{CL}_{\text {renal }}(\mathrm{L} / \mathrm{h})$ & 3 & Predicted from animal data \\
\hline CYP3A4 $\mathrm{K}_{\mathrm{i}}(\mu \mathrm{M})$ & 108 & Measured in vitro \\
\hline CYP3A4 K $(\mu \mathrm{M})$ & 163 & Measured in vitro \\
\hline CYP3A4 $\mathrm{k}_{\text {inact }}\left(\mathrm{h}^{-1}\right)$ & 1.8 & Measured in vitro \\
\hline
\end{tabular}


Table S11. Predicted pharmacokinetic parameters of PF00835231 with and without coadministration of itraconazole.

\begin{tabular}{cccccccc}
\hline PF-07304814 $^{\mathbf{a}}$ & $\begin{array}{c}\text { Itraconazole } \\
\text { mg/day }\end{array}$ & \multicolumn{2}{c}{$\mathbf{C}_{\max }$} & \multicolumn{2}{c}{ AUC } & $\mathbf{C}_{\max } \mathbf{R}$ & AUCR \\
\hline 500 & 0 & 1.1 & 0.50 & 27 & 12 & 2.1 & 2.1 \\
& 200 & 2.4 & 1.1 & 58 & 26 & $(2.1-2.3)$ & $(2.0-2.2)$ \\
\hline
\end{tabular}

Data are expressed as geometric mean for $\mathrm{C}_{\max }$ and $\mathrm{AUC}$ and geometric mean with $90 \%$ confidence intervals in parentheses for $\mathrm{C}_{\max } \mathrm{R}$ and AUCR.

a Daily dose of PF-07304814 provides formation of PF00835231 equivalent to 320mg/day used in the simulation. 
Table S12. Human and HIV Protease and Substrate concentrations.

\begin{tabular}{|l|l|l|l|}
\hline Protease/class & Enzyme (nM) & Substrate & Substrate $(\boldsymbol{\mu M})$ \\
\hline Caspase 2/ cysteine & 10 & Ac-LEHD-AMC & 5 \\
\hline Cathepsin B/ aspartyl & 1.2 & CBZ-Arg-Arg-AMC & 15 \\
\hline Cathepsin D/ aspartyl & 1.0 & $\begin{array}{l}\text { MCA-PLGL-Dap(Dnp)-AR- } \\
\text { NH2 }\end{array}$ & 2 \\
\hline Chymotrypsin/ serine & 0.5 & Suc-AAPF-AMC & 10 \\
\hline Elastase/ serine & 0.6 & MeOSuc-AAPV-AMC & 10 \\
\hline HIV-1/ aspartyl & 20 & Anaspec SensoLyte & 10 \\
\hline Thrombin a/ serine & 0.01 & $\begin{array}{l}\text { H-D-CHA-Ala-Arg- } \\
\text { AMC.2AcOH }\end{array}$ & 10 \\
\hline
\end{tabular}

